CIUDAD Y TERRITORIO

ESTUDIOS TERRITORIALES

ISSN(P): 1133-4762; ISSN(E): 2659-3254

Vol. LIII, № 207, primavera 2021

Págs. 119-140

https://doi.org/10.37230/CyTET.2021.207.07

CC BY-NC-ND

\title{
Propuesta metodológica para el estudio de las vías pecuarias desde el paisaje. Aplicación al Cordel de Gambogaz (Sevilla)
}

\author{
Carmen Venegas-MorenO ${ }^{(1)}$ \\ Irena GARCíA-VÁZQUEZ ${ }^{(2)}$ \\ Jesús RodríGUEZ-RodRíGUEZ ${ }^{(3)}$ \\ Ana Coronado-SÁnCHEZ ${ }^{(4)}$ \\ Juan José Domínguez-VeLA ${ }^{(5)}$ \\ Belén Pedregal-Mateos ${ }^{(6)}$
}

${ }^{(1)(2)(3)(4)(5) I n v e s t i g a d o r e s ~ d e l ~ C e n t r o ~ d e ~ E s t u d i o s ~ P a i s a j e ~ y ~ T e r r i t o r i o-U n i v e r s i d a d ~ d e ~ S e v i l l a . ~}$

(6) Profesora Departamento de Geografía Humana de la Universidad de Sevilla.

Directora del Centro de Estudios Paisaje y Territorio

RESUMEN: La relación entre el andar, la contemplación del paisaje y la red de caminos y vías pecuarias se argumenta recurriendo al origen de dichas vías, es decir, caminos trazados para facilitar el traslado de animales al ritmo lento de rebaños y pastores. Aunque en la actualidad la función trashumante es residual, las vías pecuarias están siendo recuperadas y utilizadas por las administraciones competentes con el objetivo de mejorar la articulación del territorio por el que transcurren, favorecer la biodiversidad y la diversificación paisajística en entornos urbanos y, en gran medida, para dar respuesta a las nuevas demandas ciudadanas relacionadas con el esparcimiento y las actividades deportivas y lúdicas propias de la sociedad actual. Este trabajo realiza una propuesta metodológica para estos itinerarios públicos desde la intervención en el paisaje, tomando como caso de estudio una vía pecuaria del Corredor Verde Metropolitano de Sevilla, el Cordel de Gambogaz, que discurre entre la capital hispalense y la localidad de Santiponce.

PALABRAS CLAVE: Paisaje en movimiento; Vías pecuarias; Caracterización paisajística; Propuesta metodológica. 


\title{
Methodological proposal for the study of livestock trails from the landscape. Application to the Cordel de Gambogaz (Seville)
}

\begin{abstract}
The relationship between walking, the contemplation of the landscape and the network of roads and livestock trails is argued by resorting to the origin of these roads, that is, trails designed to facilitate the movement of animals at the slow pace of herds and shepherds. Although the function of transhumance is currently residual, the livestock trails are being recovered and used by the competent administrations, with the aim of improving the articulation of the territory through which they pass, favoring biodiversity and landscape diversification in urban environments and, to a large extent, responding to the new citizen demands related to leisure, sports and recreational activities typical of today's society. This work makes a methodological proposal for these public itineraries from the intervention in the landscape, taking as a case study a livestock trail of the Metropolitan Green Corridor of Seville, the Cordel de Gambogaz, which runs between the capital of Seville and the town of Santiponce.
\end{abstract}

KEYWORDS: Moving landscape; Livestock trails; Landscape characterization; Methodological proposal.

\section{La percepción del paisaje ${ }^{1}$}

a Geografía de la percepción es una línea de investigación útil para el estudio del paisaje, ya que la observación del espacio que se habita explica en cierta medida el comportamiento geográfico y su relación con el paisaje (CAPEL, 1973; BERTRAND, 1978). Desde este enfoque, la fuente más común para el conocimiento subjetivo del paisaje es la construcción mental, a modo de croquis, que elabora un individuo respecto a la forma del territorio.

En relación con la elaboración individual de un mapa o croquis mental de un paisaje que se recorre, se toma como punto de partida la capacidad innata que el ser humano posee para interpretar el espacio (impresión consciente de la realidad física del entorno), entendiendo este espacio como un lugar de experiencia, de existencia o espacio vital. Igualmente lleva a cabo una simplificación de los estímulos que percibe, sustituyéndolos por conceptos para su mejor entendimiento (TUAN, 2007). Es decir, que los sentidos modifican los datos objetivos del mundo exterior, proporcionándoles cualidades que son puramente subjetivas (CAPEL, 1973), manifestándose dicha actividad mediante la curiosidad o la atención. Así la atención supone una actividad de la conciencia, en la medida en que una vez percibido, construye un objeto nuevo que antes aparecía indeterminado, por lo que la percepción conlleva la aprehensión y captación del objeto de manera unificada y cualificada (MERLEAUPONTY, 1975).

\footnotetext{
${ }^{1}$ Este artículo surge a partir de un trabajo técnico denominado Estudio para la determinación de criterios paisajísticos en la red de vías pecuarias de Andalucía, realizado en el Centro de Estudios Paisaje y Territorio-Universidad de Sevilla
}

Se considera pues que la atención es la responsable de mantener el control de la mirada y del conocimiento y, en el caso de que la experiencia decepcione o se frustre, se busca otra novedad o estímulo más satisfactorio. En este sentido, la curiosidad es una actividad proactiva que permite tomar decisiones en relación con el entorno o medio vivido, siendo un comportamiento que puede llevar a que se actúe o modifique el medio real o territorio atribuido (CAPEL, 1973; BESSE, 2010). Además, la forma en que se percibe este espacio vivido viene determinada por el modo en que las personas establecen vínculos funcionales o afectivos con dicho espacio, existiendo generalmente coincidencias entre los miembros de un mismo grupo cultural.

En suma, la percepción del paisaje viene conformada por representaciones vinculadas al entorno cultural del observador, por experiencias, recuerdos e intenciones individuales, así como por las formas físicas y espacios materiales que se expanden ante sus ojos. En este sentido, se entiende que una parte de la percepción tiene un marcado componente subjetivo y propio y que otra parte presenta un destacado trasfondo sociocultural que viene, en gran medida, conformado por convenciones sociales acerca de cómo valorar e interpretar lo que se percibe (Cosgrove, 2002). En esta misma línea, Nogué señala que el paisaje real está teñido de arquetipos que son transmitidos de generación en generación y que cada época, cada cultura, se identifica particularmente con determinadas formas del paisaje (NoguÉ, 2007). Por tanto,

a petición de la Secretaría General de Ordenación del Territorio y Sostenibilidad Urbana (SGOTSU) de la Consejería de Medio Ambiente y Ordenación del Territorio, Junta de Andalucía en 2018. 
se podría afirmar que la percepción del paisaje constituye una proyección de la propia identidad personal y social (GovindA, 2014).

Siguiendo esta línea de reflexión, en general, se considera que para percibir e interpretar el paisaje, además de una capacidad innata, se requiere un cierto diálogo entre sensibilidad y cultura para que la experiencia de percibir se torne consciente y se traduzca en una actividad o compromiso con el espacio vivido. En este proceso dialéctico entre sujeto y espacio vivido interviene la conciencia y su complejo funcionamiento, favoreciendo el reconocimiento de los lugares, su rememoración, y su integración mediante un sistema de signos y señales con origen en la propia cultura del sujeto.

En este sentido, según Luginbühl, se pueden distinguir tres niveles en cuanto a las relaciones que se establecen con el paisaje: una escala global fundamentada en la cultura; una escala local que deriva de las relaciones que vinculan al hombre con el medio y una escala individual según la cual, cada persona experimenta el paisaje de forma subjetiva (LUGINBÜHL, 2007; ORTEGA, 2010).

De esta forma, la sensibilidad necesaria para percibir el paisaje se entiende como manifestación natural de la inteligencia, de la forma de ver y de disfrutar del mundo. Asimismo, se ha dicho que en el caso de la cultura occidental contemporánea su visión del paisaje es muy intelectualizada y se percibe más a partir de ideales, aspiraciones y expectativas que de la observación diaria del entorno cotidiano (EsPAÑOL, 2007).

\section{El paisaje en movimiento}

A este proceso de percepción del paisaje se le puede sumar una circunstancia más, y es la relativa al movimiento. Esta apreciación dinámica convierte el itinerario en un hilo conductor de una sucesión de paisajes. La lectura y consideración del paisaje desde el movimiento como recuerdo personal no es nueva, ya a principios del siglo XVIII surgen los primeros intentos de establecer una relación teórica y práctica entre el caminar, el territorio y sus paisajes. Se llega a señalar que el espacio vivido es experimentado en gran medida en movimiento por un sujeto que lo codifica y dota de significado, siendo a su vez este sujeto, transformado por dicha experiencia sensorial. En este sentido, la forma contemporánea más auténtica de conocer el paisaje es recorrerlo a pie (KESSLER, 2000). Así, la información relativa al paisaje recorrido llega al sujeto a través de su sistema de receptores que, a su vez, es filtrada por el conjunto de valores individuales y colectivos. A partir de ello se elabora una imagen mental que tiene como referencia aquellos objetos que despiertan o fundamentan la atención. En esta operación perceptiva, ciertas imágenes estimulan el interés del espectador y se descartan otras, bien sea por similitudes o por diferencias y así se llega a organizar el espacio atravesado o recorrido.

En la selección de las imágenes mentales de los paisajes recorridos, aunque la vista predomina, la base de la relación observador-entorno se encuentra en el conjunto de los sentidos (la vista, el oído, el olfato, el gusto, el tacto) y en la memoria social (historia, origen, mitos...); y en general viene mediatizada por la experiencia personal. De modo que la vista, selecciona, ordena, categoriza objetos y dota de significado lo que se ve, siguiendo modelos aprendidos o pautas culturales. Se trata de un proceso continuo y dinámico entre sujeto (individuo) y objeto en movimiento (paisaje) fruto de la observación y el reconocimiento o identificación; lo que Roger denomina una artealización o interpretación de la realidad (Roger, 2007).

Esta interpretación tiene una estructura o delimitación espacio/temporal y posee un gran valor descriptivo mediante asociación y disgregación de ideas enlazadas unas con otras de manera espontánea, personal y subjetiva, y a una escala de proximidad o inmediatez. Así pues, en la percepción del recorrido se opera selectivamente, es decir, se eligen solo algunos elementos o aspectos significativos del paisaje; entre otros, ciertas referencias o puntos singulares del entorno que resultan llamativos para la atención y que suelen disponer de una carga de significado más o menos importante.

Además, el desplazamiento tiene el poder de crear formas y de comprender los elementos del paisaje en todo su significado y perspectivas: vista lateral, frontal, rodear, estar dentro, o situarse fuera, bajar o subir y, finalmente, la cuarta dimensión, que se entiende como el tiempo que transcurre mientras se desarrolla la secuencia visual. Así, el itinerario paisajístico se desarrolla a modo de una construcción mental, sólo perceptible mediante secuencias temporales encadenadas.

En general el grado de legibilidad del paisaje recorrido depende en cierta manera de la facilidad en que se identifiquen sus secuencias temporales y se integren en sus tramos, sus hitos, sus bordes o límites, dentro de un esquema global que a su vez se apoya en las experiencias sensoriales del sujeto, que conectan directamente con los recuerdos presentes y pasados para finalmente extraer de todo ello un sistema de orientación a modo de croquis. De modo que en un itinerario se encuentra un inicio, un final, tramos, límites, umbrales, hitos y elementos (APPLEYARD \& LYNCH \& MYER, 1971). 
Como se viene señalando, andar es la primera experiencia de vida que implica tomar conciencia del espacio próximo o afectivo, de habitarlo, de atravesarlo y, a la vez, supone el modo más natural de retener y memorizar el espacio recorrido, estando en general al alcance de cualquier persona. Igualmente, permite desarrollar todas las capacidades de percepción del paisaje -desde la configuración de un esquema mental hasta su compresión global-, siendo una forma y método perceptivo de conocimiento del entorno basado principalmente en las asociaciones de ideas generadas por las propias condiciones de la marcha, convirtiendo el propio cuerpo en un sistema de medición de las coordenadas antropológicas fundamentales (espacio/tiempo) que permiten descubrir la verdadera dimensión espacial de las distancias.

En este sentido, en los últimos años, profesionales de la arquitectura del paisaje ${ }^{2}$ con precedentes en corrientes culturales y artísticas occidentales que se desarrollaron en la segunda mitad del siglo XX -como el Situacionismo y el Land Art-, explican que el acto de andar en grupo proporciona nuevas claves que permiten profundizar en su interpretación; una experiencia que facilita el desarrollo de nuevas formas de comprender los lugares de una manera sensible e imaginativa y en la cual el camino es utilizado como hilo conductor. En esta experiencia sucede que la atención no es siempre uniforme. De modo que las escenas recorridas, aunque sean de manera casual o espontánea, despiertan una curiosidad desigual, quedando en la memoria una impresión compuesta de detalles concretos y de una idea general más o menos abstracta que se puede recordar, describir, interpretar o verificar y se configura bajo la forma de un relato (CABALLERO \& Domínguez \& ZOIDO, 2016).

\section{La percepción del paisaje en movimiento a través de las vías pecuarias}

La relación entre el andar, la red de caminos y vías pecuarias existentes y la contemplación del paisaje se argumenta de manera muy sencilla recurriendo al origen de dichas vías, es decir, caminos trazados para el movimiento del ganado, formulados para facilitar el traslado de animales al ritmo lento de rebaños y pastores. Se entiende que estos caminos

\footnotetext{
${ }^{2}$ Un ejemplo de interés es la experiencia "Stalker/ Osservatorio Nomade" formada por un colectivo de arquitectos e investigadores vinculados a la Universidad de Roma Tre que creó a mediados de los noventa una red de investigación para trabajar de manera experimental en las ciudades, mediante herramientas participativas. Para ello realizan paseos
}

eran, en otro tiempo, lugares simbólicos -símbolos públicos y áreas de cuidado, según Yi-Fu Tuan (TUAN, 2018)-, donde se desarrollaba la vida de ciertas comunidades nómadas. Y en este caminar trashumante se progresa al ritmo propuesto por los lugares; unas veces con paso más rápido, otras con paso lento y siempre de acuerdo o en sintonía con la diversidad del territorio que se atraviesa, permitiendo la contemplación e interpretación del paisaje que los rodea.

Si bien esa función trashumante ha pasado a ser residual en muchos casos, los caminos y vías pecuarias están siendo recuperados por las administraciones competentes en la actualidad para aprovechar esta gran red territorial con el objetivo de mejorar la articulación del territorio, favorecer la biodiversidad y la diversificación paisajística en entornos urbanos y, en gran medida, para dar respuesta a las nuevas demandas ciudadanas relacionadas con el esparcimiento y las actividades deportivas y lúdicas propias de la sociedad actual.

El progresivo reconocimiento de las vías pecuarias se culmina en España con la Ley 3/1995 de 23 de marzo (BOE 71/1995) en la que quedan plasmados, por primera vez en un documento de esta naturaleza, los usos y funciones que esta amplia red de caminos cumple en la actualidad. Así, tal y como señala Manteca Valdelande, las vías pecuarias, antes de la entrada en vigor de la ley, prestaban fundamentalmente dos servicios: comunicar áreas de pastoreo estacional y alimentar el ganado en ese tránsito. Con la nueva normativa, las vías pecuarias pasan a asumir otras funciones adicionales como servir de corredores ecológicos o como instrumento que contribuye a favorecer el contacto entre el hombre y el medio. Esta ley añade por tanto al uso tradicional otros usos compatibles y complementarios, como la práctica del senderismo, la cabalgada y otras formas de desplazamiento deportivo sobre vehículos no motorizados (MANTECA, 1995:153-154).

La citada Ley tiene su desarrollo en Andalucía mediante el Decreto 155/1998 de 21 de julio, por el que se aprueba el Reglamento de Vías Pecuarias de la Comunidad Autónoma de Andalucía (BosA 87/1998) en el que además de disponer los instrumentos necesarios para la protección de este patrimonio, se destaca su interés dada su enorme continuidad en el territorio andaluz, sus funciones ambientales y su carácter de dominio público.

por los espacios "indeterminados" o vacíos de la ciudad, que son ignorados o considerados un problema en la práctica urbana tradicional. Esta idea de caminar es utilizada como herramienta para reconocer la ciudad y sus transformaciones, evocar recuerdos y experiencias, y usar este conocimiento para abordar cuestiones de planificación urbana y territorial. 
Andalucía cuenta con una extensa red de vías pecuarias con una extensión de 34.082 kilómetros de longitud (IMA, 2018), siendo la Comunidad Autónoma que presenta la red más amplia dentro del territorio nacional.

Atendiendo a sus dimensiones, y siguiendo la clasificación básica de la red de vías pecuarias en cañadas (75 $\mathrm{m}$ de anchura), cordeles $(37,5 \mathrm{~m})$ y veredas $(20 \mathrm{~m})$, en Andalucía existen en torno a 8 mil kilómetros de las primeras, 7 mil de las segundas y 13 mil de las terceras. Pero, además, estas vías principales articulan el espacio y se conectan entre sí a través de otros ramales y coladas, en torno a 5 mil kilómetros, y se complementan con todo un conjunto de elementos de interés etnográfico como los abrevaderos, descansaderos, majadas, etc., asociados al tránsito ganadero (FIG.1).

Siguiendo los preceptos del reglamento de vías pecuarias de la región, se ha desarrollado el Plan para la Recuperación y Ordenación de la Red de Vías Pecuarias de la Comunidad Autónoma de Andalucía (BojA 74/2001), con la finalidad de dotar a esta extensa red de una dimensión de utilidad pública más allá del uso tradicional ganadero, destacando sus funciones medioambientales, paisajísticas, de desarrollo rural y de esparcimiento ciudadano.

En este sentido, el plan considera las vías pecuarias desde una triple perspectiva: (1) como elemento vertebrador del territorio y, concretamente, posibilitando la conexión del sistema urbano con los recursos naturales del entorno, propiciando la diversificación del paisaje o incidiendo en la planificación de las ciudades; (2) como elemento fundamental en la planificación ambiental, concretándose este papel en el establecimiento de corredores ecológicos y (3) como elementos que favorecen la fijación de la población en zonas rurales degradadas, por su alto potencial para el desarrollo de actividades socioeconómicas.

Así, en función de los usos previstos para cada ruta, ya sean rutas ganaderas, rutas turísticorecreativas o rutas ecológicas, se recogen las actuaciones específicas que se precisan para su recuperación y ordenación. En el caso específico de las rutas turístico-recreativas se destaca la necesidad de adecuación del firme para facilitar actividades de ocio, tales como el senderismo a pie, en bicicleta o a caballo; la instalación de

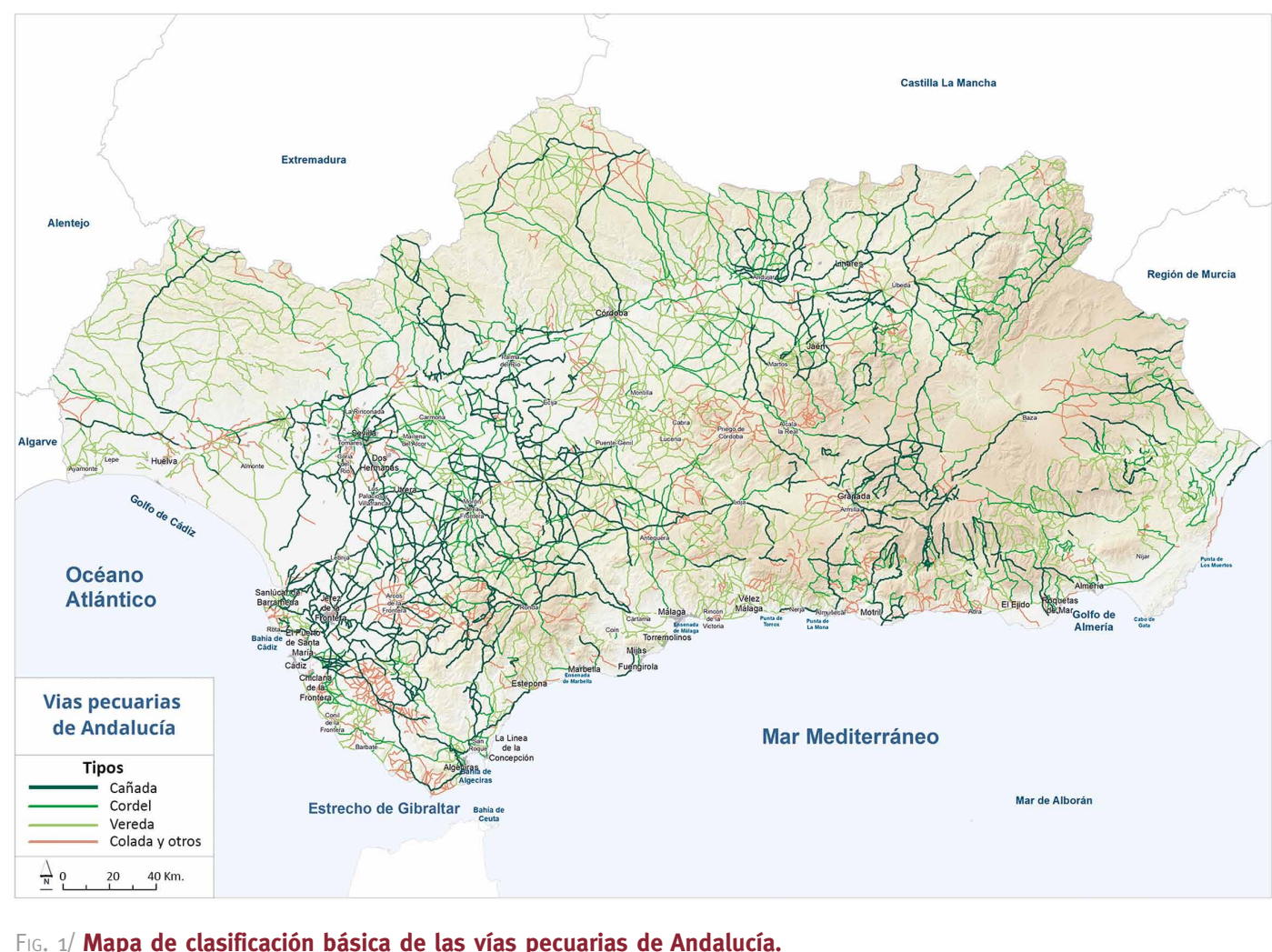

Fuente: Elaboración propia. 
equipamientos de uso público ligeros y las plantaciones a fin de conseguir una mejora paisajística, haciendo más atractivo el uso de las vías pecuarias como itinerarios de paseo, sobre todo en los entornos urbanos.

Por todo ello, resulta evidente que se trata de un importante patrimonio que tiene un profundo sentido histórico y, aunque las funciones seculares que dieron origen a estas vías se han ido perdiendo con el paso del tiempo, hoy sigue configurando un amplio soporte que adquiere nuevos usos al permitir a la ciudadanía salir fuera de los entornos urbanos, recorrer sus territorios y acceder a los paisajes, mediante formas de movilidad lentas, que permiten un acercamiento más directo y pausado. En esta idea también inciden distintas organizaciones ecologistas y sociales, desde las que se plantea la necesidad de favorecer la función social de estas vías, entendiendo que se hace necesario dotarlas de nuevas funcionalidades que impidan su abandono o usurpación, impulsando proyectos para su recuperación ecológica y paisajística y potenciando su uso recreativo, turístico y medioambiental, compatibilizándolo con su ancestral uso pecuario (CLAVERo, 2001).

Las vías pecuarias, por tanto, responden de manera idónea a las actuales tendencias de ocio relacionadas con la práctica deportiva y de esparcimiento, que se muestran atraídas por lugares considerados de interés ambiental, paisajístico, cultural o histórico, y asumen que pasear y andar pausadamente es una manera de conocerlos, además de una experiencia física y mental saludable.

Como señala Calvo Salazar la "red de vías pecuarias ha sido creada con criterios muy diferentes a cualquier otra red de comunicaciones actual". Estos caminos respetan el relieve en su trazado, conectan el sistema de asentamientos y ofrecen la posibilidad de recorrer el territorio de forma diferente, adaptándose a la escala humana. Así, la red de vías pecuarias facilita una aproximación distinta del ciudadano con el medio rural, más cercana a la percepción, donde cobran importancia otros sentidos como el oído, el olfato o el tacto en la contemplación de los paisajes (CALVo, 2001: 129).

Así pues, y siguiendo esta lógica, se está redescubriendo el caminar como una fuente de estímulos y el pasear como una elección vital o filosofía que permite percibir la belleza del camino en sí (CABAllero \& Domínguez \& Zoido, 2016). Esto es, la extensión del paisaje en sus márgenes y la consideración de sus pequeños detalles. Se trata de una visión estética o contemplativa de la naturaleza asociada a una emoción vivencial enriquecedora y agradable que aporta calidad de vida, en línea con los planteamientos que recoge el Convenio Europeo del Paisaje (CONSEJO dE EUROPA, 2000).

\section{Propuesta metodológica para el estudio y puesta en valor de una vía pecuaria desde un enfoque paisajístico}

Tomando como marco conceptual y normativo de referencia el Convenio Europeo del Paisaje, documento en vigor en España desde 2008, se han realizado numerosos trabajos que han intentado avanzar en el conocimiento, la conservación y gestión de los paisajes a través del desarrollo de procesos metodológicos, políticas e intervenciones de muy distinta naturaleza. En esta misma línea se inserta el presente trabajo, centrado en profundizar y poner en valor las estrechas relaciones que se establecen entre paisaje, movimiento y vías pecuarias a partir del desarrollo de una propuesta metodológica que favorezca la puesta en valor y cualificación de estas vías históricas para su uso y disfrute público.

En el desarrollo de esta propuesta metodológica se han tomado como referentes principales los estudios realizados en el Centro de Estudios Paisaje y Territorio de Andalucía, donde, a partir de la adaptación de la metodología británica del Landscape Character Assessment, se han desarrollado diferentes trabajos de caracterización de los paisajes de Andalucía, como la elaboración del Inventario de Recursos y el Sistema Compartido de Información sobre el Paisaje de Andalucía (ZoIDo, 2014) o el desarrollo de la metodología de los Catálogos de Paisaje de Andalucía y su aplicación a las provincias de Sevilla (ZoIDo \& Rodríguez, 2015), Granada y Málaga.

Asimismo, el citado Centro de Estudios ha desarrollado una línea específica de trabajo sobre las relaciones existentes entre paisaje e infraestructuras, con trabajos novedosos de gran utilidad que pueden ser considerados antecedentes de gran interés en la consideración del paisaje desde una perspectiva lineal (FERnÁndez \& Silva, 2015; ZoIDO, 2009; Las carreteras paisajísticas de Andalucía. Recurso para el disfrute y aprecio social del paisaje, 2017). De esta forma, este trabajo continúa esta línea de investigación teniendo en cuenta las particularidades de las vías pecuarias: itinerarios que se recorren lentamente, a pie o en bici, cuyo trazado está preestablecido y al que hay que dotar de una lectura paisajística.

Partiendo de estos conceptos e ideas y tomando como referentes metodológicos y conceptuales los trabajos anteriormente señalados, a continuación se detalla el proceso metodológico propuesto para la consideración de las vías pecuarias desde el paisaje como base para el desarrollo de futuras actuaciones encaminadas a la puesta en valor y uso social de estos itinerarios públicos. 
Esta propuesta metodológica se plantea con una estructura y contenidos mínimos que puedan ser comunes al conjunto de vías pecuarias con el objeto de favorecer el disfrute y aprecio social de los recursos paisajísticos asociados a dichas vías. En este sentido, se proponen cuatro fases de trabajo esenciales (FIG. 2): (1) planteamiento inicial y contextualización territorial de la vía pecuaria considerada; (2) análisis y caracterización paisajística; (3) diagnóstico paisajístico y (4) criterios y propuesta para la cualificación paisajística de la vía pecuaria. A continuación se explicitan cada una de ellas.

\subsection{Planteamiento inicial y contextualización territorial}

En primer lugar, imprescindible en cualquier trabajo con una dimensión espacial, se ha de realizar una contextualización territorial del ámbito por el que discurre la vía pecuaria considerada. El alcance de dicha contextualización se puede concretar dependiendo de las características formales de la vía y en función de diversas circunstancias como:

- la continuidad paisajística o escénica del ámbito en el que se inserta la vía;

- los rasgos, estructuras o componentes, tanto naturales como antrópicos, que definen el carácter del paisaje recorrido;

- la presencia de hechos territoriales de gran entidad que incidan de manera significativa en el propio recorrido pecuario;

- la existencia de una red de vías pecuarias o de otros itinerarios de uso público que permitan realizar un tratamiento conjunto de la misma para el disfrute y uso social;

- las determinaciones que la planificación física o sectorial recomienden respecto al tratamiento de un ámbito administrativamente delimitado.

Una vez establecido el alcance del contexto territorial de la vía, se ha de proceder a la descripción general del ámbito que recorre el itinerario identificado.

\subsection{Análisis y caracterización paisajística}

En relación con el análisis y la caracterización del recorrido han de abordarse los diversos aspectos que conforman la imagen paisajística del territorio, incluyendo los fundamentos naturales del paisaje, los procesos históricos que lo han ido configurando, así como las condiciones escénicas, los valores y significados que articulan su apreciación e interpretación. De manera sistemática, el reconocimiento del paisaje en el que se inserta el recorrido o camino a considerar debe comprender, al menos, los siguientes aspectos:

- Fundamentos naturales del paisaje, que incluyen no sólo los procesos de formación del relieve, sino también la evolución, diversificación o adaptación agroforestal de las formaciones vegetales naturales; las dinámicas y formas específicas que la climatología y la hidrología presentan en el contexto territorial de referencia; las limitaciones o potencialidades que la edafología o el relieve plantean a los sistemas de ocupación y aprovechamiento del territorio; etc.

- Procesos históricos que abarcan desde el desarrollo del hábitat humano y sus sistemas (asentamientos, ciudades, etc.) hasta los aprovechamientos del medio y cómo han evolucionado, destacando, para ello, las principales evidencias que muestren estos procesos culturales al observador.

- Percepciones y representaciones, que comprenden los significados adscritos al paisaje por las distintas culturas que se han aproximado a él, así como la interpretación de estos significados por la sociedad.

La idea esencial de este proceso de partida es plantear un análisis diacrónico de cómo todas estas dinámicas (naturaleza, cultura, interpretación simbólica) se han superpuesto y han interactuado a lo largo del tiempo y, sobre todo, cómo se muestran en el paisaje actual.

Una vez caracterizado el itinerario en su contexto paisajístico, el análisis se centra en el propio itinerario, destacando las condiciones de su recorrido, su conectividad con otros viarios, las condiciones escénicas que presenta, los recursos patrimoniales existentes y las incidencias que las políticas territoriales y urbanísticas tienen en el mismo.

Por lo que respecta al reconocimiento de las condiciones materiales y funcionales del itinerario resulta imprescindible realizar el trabajo de campo asociado que permita identificar cuestiones de interés como el estado del firme, la vegetación existente y las zonas de sombra, el uso que se hace del itinerario, etc. En definitiva, se trata de conocer las condiciones de partida del recorrido en el que se va a intervenir.

Igualmente, resulta necesario conocer la articulación y conectividad de la vía, tanto con la red de carreteras existente como con otros itinerarios de uso público que fomenten el establecimiento de una red en la que pudiera insertarse dicha vía. Asimismo, la conexión con espacios libres próximos al itinerario permite desarrollar una estrategia de disfrute completa y diversificada. 
En esta fase de análisis también es imprescindible abordar el estudio de las condiciones escénicas y de visibilidad que presenta el itinerario, con el objeto de conocer aquellos espacios del entorno de la vía que presentan una mayor o menor exposición visual, así como los puntos desde los que se obtienen las vistas más significativas desde el recorrido. En esta misma línea, se hace necesario la identificación de los recursos patrimoniales, tanto naturales como culturales, existentes que en muchos casos se convierten en los hitos paisajísticos del itinerario.

Finalmente, en esta fase analítica se hace necesario tomar en consideración las determinaciones de los distintos documentos de planificación física que afectan a la vía y su entorno, ya que las actuaciones previstas en los planes territoriales y urbanísticos de los espacios próximos al recorrido tienen una gran incidencia en las condiciones y usos del mismo.

\subsection{Diagnostico paisajístico}

A partir del análisis realizado, la siguiente fase metodológica supone la elaboración de un diagnóstico de los procesos del paisaje, de sus dinámicas, así como de los rasgos fundamentales que muestran. Este diagnóstico, que ha de ser sintético, debe identificar los principales valores y conflictos que se observan en el itinerario de la vía pecuaria y su entorno próximo.

En relación con los valores, se deben tomar en consideración los recursos y potencialidades del itinerario analizado. Para ello, se han de identificar aquellas circunstancias y elementos que contribuyen de manera significativa a la calidad paisajística del territorio por el que transcurre la vía pecuaria.

Por otro lado, deben identificarse también aquellas circunstancias que suponen un conflicto o amenaza para la calidad paisajística de la vía considerada o de su entorno inmediato.

\subsection{Criterios y propuesta para la cualificación paisajística de la vía pecuaria}

Finalmente, la caracterización y análisis previo permiten establecer el marco de intervención de la propuesta. Para el desarrollo de ésta, y como paso previo al propio proyecto de intervención, se han de establecer los criterios para la cualificación paisajística de la vía pecuaria considerada. Estos criterios han de ir encaminados no sólo a la adecuación de la vía pecuaria, sino también al fomento de los paisajes por los que transcurre.

Las propuestas planteadas para la vía pecuaria pueden ser muy diversas y dependerán de las características y circunstancias de la misma y de su entorno territorial, si bien se deberían establecer al menos criterios específicos en relación con: el tratamiento de las condiciones de la propia vía; la identificación y señalización del itinerario; la cualificación ambiental del recorrido; la puesta en valor de los elementos sobresalientes próximos; la integración paisajística de elementos discordantes y la divulgación y fomento del uso social y disfrute del itinerario.

Síntesis del proceso metodológico

PLANTEAMIENTO INICIAL Y CONTEXTUALIZACIÓN TERRITORIAL DE LA VÍA PECUARIA

$1 \quad$ Contextualización territorial

Descripción general del ámbito

ANÁLISIS Y CARACTERIZACIÓN PAISAJÍSTICA

Caracterización de los procesos y componentes del paisaje

Fundamentos naturales

Procesos históricos

Percepciones y representaciones

$2 \quad$ Análisis de las condiciones del itinerario

Condiciones de la vía

Conectividad y articulación

Condiciones escénicas y visibilidad

Identificación de recursos patrimoniales

Incidencias territoriales y urbanísticas

DIAGNÓSTICO PAISAJÍSTICO

$3 \quad$ Identificación de valores, recursos y potencialidades

Identificación de conflictos y/o amenazas para la cualificación de la vía

CRITERIOS Y PROPUESTA PARA LA CUALIFICACIÓN PAISAJISTICA DE LA VÍA PECUARIA

$4 \quad$ Tratamiento de la vía y señalización

Cualificación ambiental del recorrido

Divulgación e integración paisajística

Síntesis del proceso metodológico para la consideración de las vías pecuarias desde el paisaje.

Fuente: Elaboración propia 


\section{Análisis de caso: Consideración paisajistica del cordel de Gambogaz de Sevilla a Santiponce}

La validación empírica del método propuesto se ha llevado a cabo en una vía pecuaria situada en el entorno de la ciudad de Sevilla, concretamente el denominado cordel de Gambogaz, que forma parte de la fase II del Corredor Verde Metropolitano de Sevilla (Coria del Río-Santiponce) y se extiende por la vega del Guadalquivir entre los municipios de Sevilla, Camas y Santiponce (Corredor Verde del Área Metropolitana de Sevilla, 2003). Este cordel se corresponde con un itinerario que tiene origen en las proximidades de Sevilla capital y continúa hasta la localidad de Santiponce con una longitud aproximada de $7,8 \mathrm{~km}$. presentando un trazado llano, de gran rectitud y orientación dominante de sentido noroeste.

\subsection{Planteamiento inicial \\ y contextualización territorial del cordel de Gambogaz}

La fase II del Corredor Verde Metropolitano, del cual forma parte la vía pecuaria del cordel de Gambogaz, en concreto en su tramo 4, se sitúa al oeste de la aglomeración urbana de Sevilla, discurriendo en un eje de norte a sur que recorre en gran parte las tierras aluviales del Guadalquivir (FIG.3).

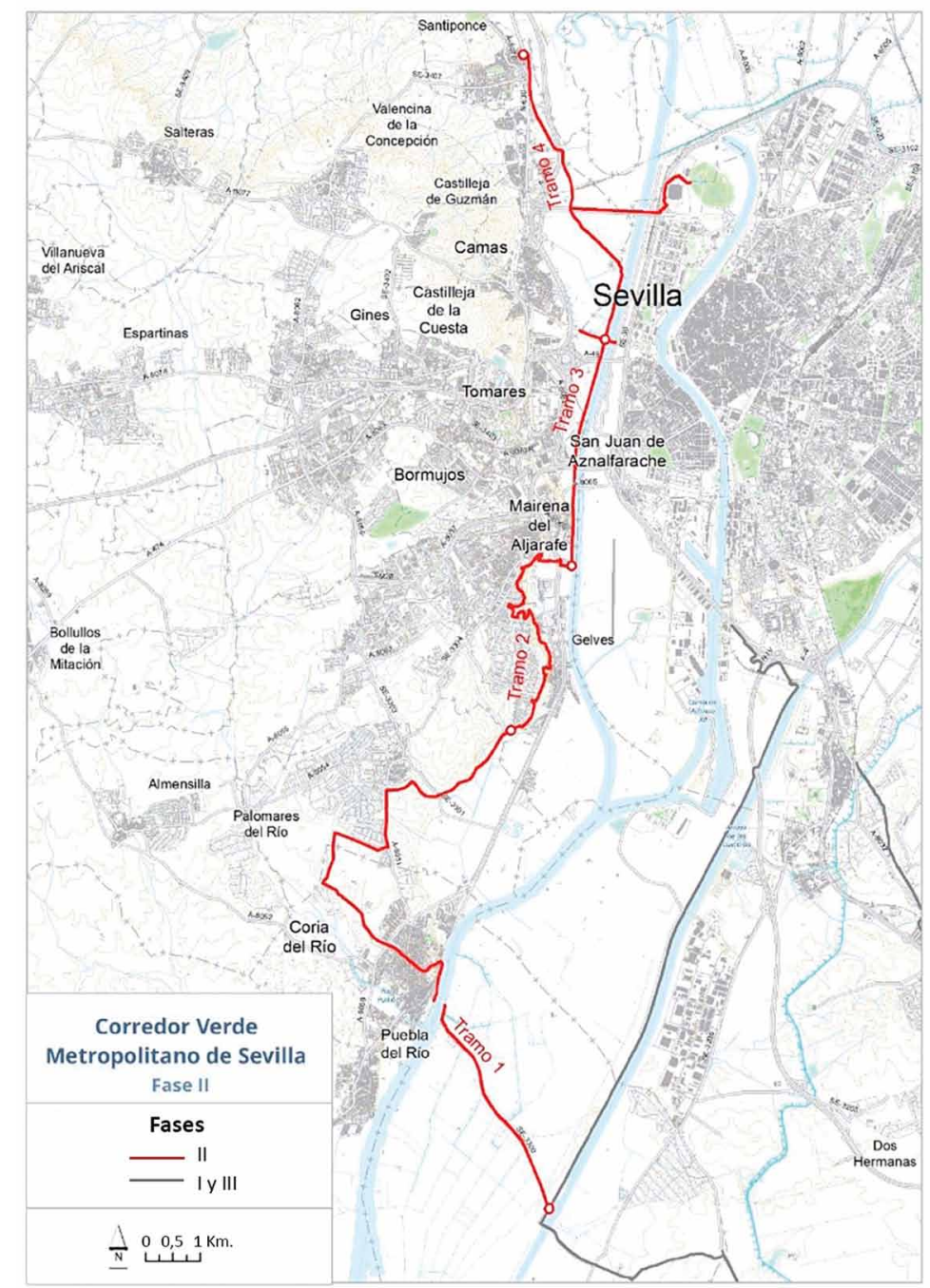

FIG. 3/ Mapa del Corredor Verde Metropolitano de Sevilla, fase II. El cordel de Gambogaz forma parte del tramo 4. 
Este espacio se puede considerar la transición entre el medio y el bajo Guadalquivir, limitando este último con la zona de marismas, aguas abajo de Coria del Río, siendo el valle del río y parte de su estuario en sentido amplio el marco geográfico de referencia. El Guadalquivir condiciona la orografía de este espacio desarrollando un relieve predominantemente llano, si bien las coberturas detríticas y depósitos de piedemonte que se desarrollan al oeste del sector de vegas y terrazas y que se muestran topográficamente elevadas respecto al mismo, presentan una importancia trascendental desde el punto de vista geohistórico para la configuración del paisaje de este territorio.

Este territorio ha sufrido una intensa ocupación a lo largo de la historia, dando lugar a un área densamente poblada cuya centralidad recae en la ciudad de Sevilla, y una red de asentamientos urbanos en su entorno metropolitano que, en el sector oeste, adquiere una gran densidad y elevada atomización de núcleos. Éstos ocupan un relieve situado a mayor altitud respecto a las vegas y terrazas (caso de los núcleos de Castilleja de la Cuesta, Tomares, Mairena del Aljarafe), existiendo otros que se sitúan, al menos parcialmente, en el escarpe de elevada inclinación de transición al valle (núcleos urbanos de Santiponce, Camas, San Juan de Aznalfarache, Gelves, Palomares del Río y Coria del Río).

Se trata de un ámbito de gran dinamismo y tensiones territoriales, propias de un espacio de vocación metropolitana, donde las funciones urbanas, comerciales e industriales y los patrones de consumo y movilidad contemporáneos asociados son los predominantes (ZOIDO \& RODRÍGUEZ, 2015).

\subsection{Análisis y caracterización paisajística}

\subsubsection{Caracterización de los procesos y componentes del paisaje}

Tal y como se recoge en el apartado 4, para abordar el análisis y la caracterización paisajística de la vía pecuaria resulta imprescindible conocer los procesos y estudiar los componentes relacionados con el paisaje por el que transcurre dicha vía. De manera sintética, a continuación se recogen los aspectos más destacados para el cordel de Gambogaz:

\section{a. Fundamentos naturales}

El marco geográfico de referencia de este corredor pecuario es el espacio de transición que se conforma entre el curso medio y bajo del río Guadalquivir, donde el elemento articulador y referente territorial de primerorden es el propio río.
El Guadalquivir y sus afluentes condicionan la topografía del valle, determinando un relieve predominantemente llano, donde el cauce, la vega y las terrazas aluviales representan el eje central del territorio. Se trata de espacios llanos, de origen aluvial donde los aportes sedimentarios han desarrollado roquedos detríticos, principalmente arenas y gravas, y donde las altitudes no superan los 10-20 metros.

Al oeste de las vegas y terrazas, en la margen derecha de río, las coberturas detríticas y los depósitos de piedemonte, formados por margosas principalmente, han supuesto la formación de un escarpe, sobreelevado respecto a éstas, que, en algunos sectores de la transición al valle -como por ejemplo entre Castilleja de Guzmán y Camas-, crea marcadas pendientes que pueden alcanzar los 100 metros.

Por el noroeste se encuentra el Campo de Tejada, unidad morfológica que conecta visualmente con las estribaciones de Sierra Morena, y que ocupa una plataforma de marcado perfil alomado, fruto de la erosión de una activa red hidrográfica sobre los materiales deleznables que la conforman.

Con carácter general, y apoyado en un benigno clima mediterráneo, este territorio posee unas condiciones edáficas favorecedoras, que ayudan a explicar la pronta ocupación humana y el establecimiento de asentamientos permanentes desde el II milenio a. C. En general los suelos del ámbito poseen una elevada fertilidad y una alta capacidad agronómica, y han sido el soporte productivo en el que se han desarrollado los usos intensivos de regadío, principalmente en las áreas de vegas, y de olivar y vides en las plataformas del Aljarafe. Estos espacios productivos se han ido reduciendo de manera significativa a medida que los desarrollos urbanos han ido extendiéndose por el ámbito, fundamentalmente en las últimas décadas del siglo XX (FIG. 4).

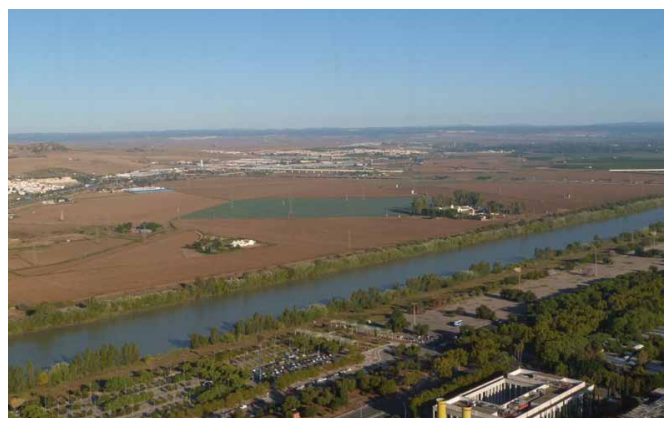

Vista del sector noroeste de la aglomeración urbana de Sevilla por el que transcurre el cordel de Gambogaz. 


\section{b. Procesos históricos}

Los condicionantes del medio físico determinaron el carácter estratégico y singular de este territorio -en la encrucijada entre la cornisa del Aljarafe y la vega del Guadalquivir y con este río como eje vertebrador-, cuyo proceso de ocupación inicial estuvo marcado por la evolución del tramo final del cauce del Guadalquivir y su desembocadura. En este sentido, el poblamiento del ámbito se inicia cuando los bordes bajos del Aljarafe y el valle aluvial del Guadalquivir se hacen habitables a finales del II mil. a. C., registrándose la presencia de los primeros poblados tartésicos en los puntos elevados.

A partir de este momento se suceden importantes transformaciones en estas fértiles tierras, como la introducción de nuevos cultivos con la llegada de los fenicios -entre los que destacan la vid y el olivo-, o la reestructuración agropecuaria que trae aparejada la entrada en la órbita romana a partir de la fundación de la colonia de Itálica en el 206 a. C. y que se irá intensificando durante los siglos de auge del Imperio.

Durante el período que transcurre desde la decadencia de la Itálica romana hasta que se hace efectivo el dominio visigodo (siglos IV al $\mathrm{VI}$ ), se va modificando el modelo de territorio y la concepción del espacio anterior, reduciéndose la población de los núcleos urbanos en favor de un hábitat rural cada vez más disperso, al tiempo que se abandonan las grandes villas en el campo. El sistema de alquerías implantado por los musulmanes recupera en parte el de las villas romanas, aunque con algunos reajustes, como la expansión del olivar o la proliferación de las huertas. Asimismo, las crónicas árabes documentan el abandono de la ciudad de Itálica y la conformación de un nuevo núcleo a orillas del río que daría lugar a la primitiva villa de Santiponce.

Tras la conquista castellana de la ciudad de Sevilla y su entorno, las tierras de Santiponce se convierten en un señorío eclesiástico y pasan a pertenecer al monasterio de San Isidoro, al igual que el cortijo de Gambogaz y sus tierras, entregados primero al Cabildo de la Catedral de Sevilla y, posteriormente, al monasterio de Santa María de las Cuevas. En esta etapa bajomedieval, la Vía de la Plata se consolida como camino y como una de las cañadas principales de la Mesta.

Las inundaciones que se suceden en 1595 y 1603 por las crecidas del Guadalquivir, suponen la destrucción del núcleo original de Santiponce y su traslado al cerro de San Antonio, más alto y protegido del alcance de las riadas, sobre las ruinas de Itálica.
Durante la primera mitad del siglo XIX, los procesos desamortizadores permitieron la adquisición de tierras por parte de la burguesía. En el caso de Santiponce, tras la desamortización del monasterio de San Isidoro en 1835, las tierras de su propiedad pasaron a manos privadas, aunque no se produjeron grandes cambios en los cultivos. En lo que respecta al cortijo de Gambogaz, que estaba en posesión de los cartujos del monasterio de Santa María de las Cuevas, fue comprado en 1851 por Ignacio Vázquez Gutiérrez, figura clave en la modernización del campo andaluz y pionero de la mecanización de las labores agrícolas y de la aplicación de técnicas agrícolas innovadoras. Tras la guerra civil española, el cortijo de Gambogaz pasó a ser propiedad del general Queipo de Llano.

En relación con las infraestructuras del ámbito, en 1903 se construye el ferrocarril de Cala a San Juan de Aznalfarache, paralelo a la carretera de Extremadura (N-630). Estuvo en uso hasta 1958 y tras su desmonte sirvió de base para la construcción en 1975 de la "autovía de Camas" en la parte final de la N-630.

Asimismo, las condiciones de navegación del cauce bajo del Guadalquivir se habían ido degradando como consecuencia de la dinámica natural del río y de la necesidad de un mayor calado. Por este motivo, los proyectos de cortas de meandros se inician a mediados del s. XVIII y continuaran a lo largo de los siglos XIX y XX, desde la corta de Merlina en 1784 hasta la de la Cartuja en 1975 Los objetivos principales eran proteger la ciudad de Sevilla de las inundaciones y facilitar la navegación hasta el mar y supusieron una importante transformación en los terrenos cercanos al río (ZoIDO, 2013).

\section{c. Percepciones}

En relación con el estudio de las percepciones, destacan las representaciones iconográficas históricas sobre el espacio que recorre el cordel de Gambogaz, vinculadas por una parte con las vistas de conjunto de la capital sevillana desde la cornisa oriental del Aljarafe y, por otra, con la presencia dominante de la ciudad romana de Itálica y del monasterio de San Isidoro del Campo, con la población de Santiponce como telón de fondo. Asimismo, el río Guadalquivir constituye un referente de primer orden, común a estas temáticas, y presente en la mayor parte de las representaciones del ámbito.

En lo que respecta a la imagen externa o de conjunto de la ciudad de Sevilla, desde el siglo XVI se desarrolla un amplio repertorio de imágenes topográficas de la ciudad como consecuencia de la importancia que adquirió Sevilla como metrópoli de las Indias, siendo 


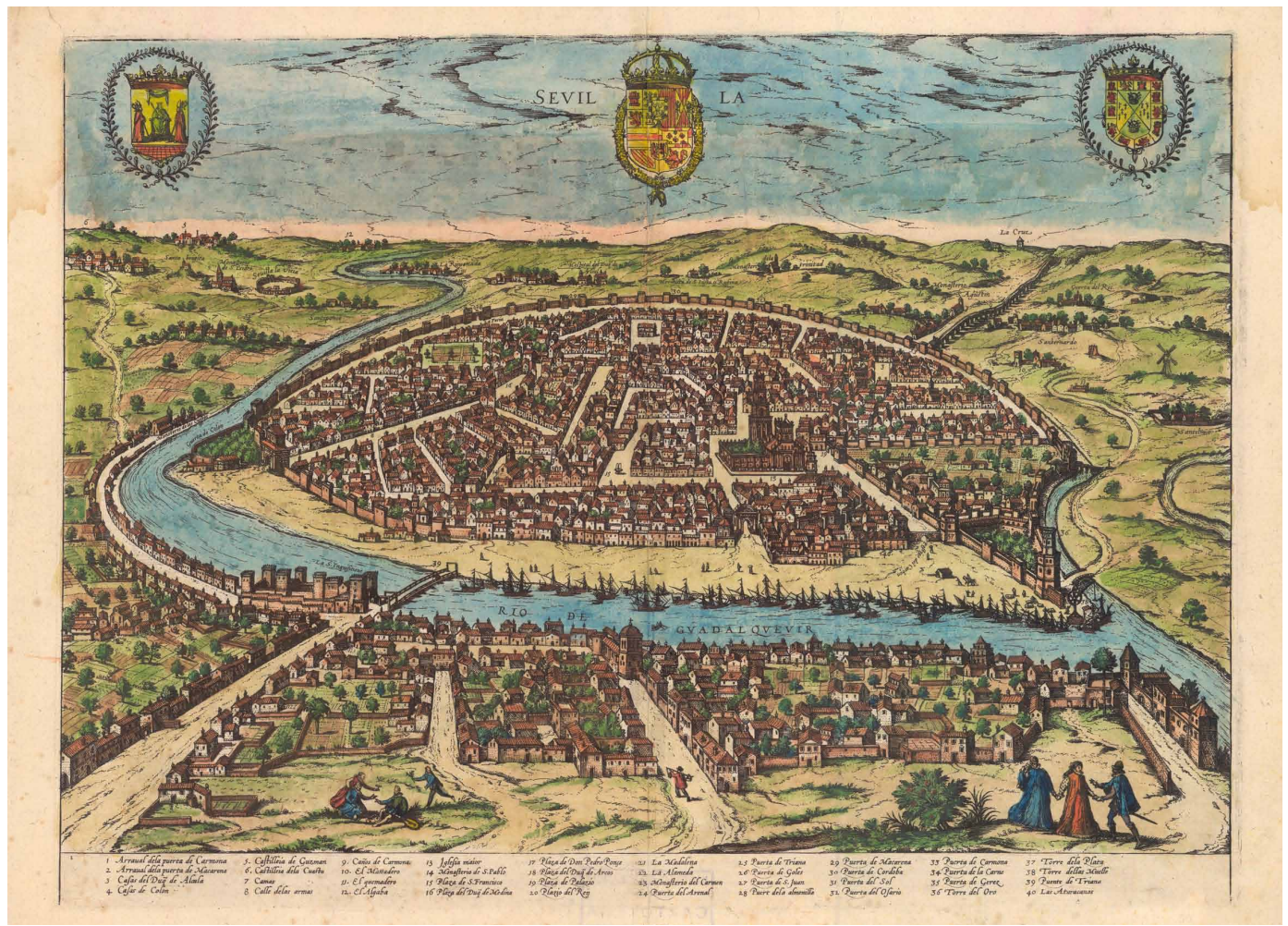

FIG. 5/ Vista general de Sevilla, copia del dibujo de A. Brambilla de $\mathbf{1 5 8 5}$ en el Civitates Orbis Terrarum, F. Hogenberg y G. Braun; Colonia, 1588.

Fuente: Instituto Geográfico Nacional, Ministerio de Fomento, 31-C-16, CC-BY 4.0. ign.es.

sus rasgos más identitarios su carácter monumental, la preeminencia de la Giralda en su perfil aéreo y la presencia del río Guadalquivir. Desde finales del siglo XVIII y durante todo el siglo XIX, las representaciones culturales de la ciudad se multiplican y este prestigio adquirido por la capital favorecerá la frecuentación por parte de los viajeros que la visitaban de otros lugares del entorno de Sevilla. En el caso del Aljarafe, las percepciones se centraron en las localidades de San Juan de Aznalfarache y de Santiponce, donde se ubicaba el monasterio de San Isidoro del Campo y las ruinas de "Sevilla la Vieja” (Itálica), destacándose en ambos casos sus valores históricos y patrimoniales (ZOIDO \& RODRÍGUEZ, 2015).

Ambas piezas comienzan a tomar protagonismo como hitos importantes del territorio. Así, las vistas generales de Sevilla y sus alrededores que se realizan a partir de la segunda mitad del s. $\mathrm{XVI}$ incorporan ya las referencias de San Isidoro del Campo y de Sevilla la Vieja, representada por su elemento más destacado, el anfiteatro.

Un ejemplo de ello es la Vista general de Sevilla, grabado de Ambrosius Brambilla realizado en 1585, en la que aparecen Itálica, el monasterio y el pueblo de Santiponce detalladamente situados al noroeste de Sevilla (FIG. 5). Esta vista de Sevilla fue muy conocida tras ser incluida en el tomo IV del Civitates Orbis Terrarum, una obra de gran difusión por toda Europa.

En los siglos XVII y XVIII, se realizan distintas obras iconográficas y cartográficas que aportan una visión detallada de cómo se encontraba el pueblo de Santiponce, Itálica, el monasterio de San Isidoro y el territorio circundante. Algunas de estas obras se centran en escenas de la vida de San Isidoro, otras en las posesiones del monasterio e incluso hay documentos de tipo administrativo, pero su interés para este trabajo reside en la representación de hitos y elementos territoriales tales como el cauce de la Madre Vieja, el curso del Guadalquivir, el trazado urbano del nuevo núcleo de Santiponce, los cortijos, el trazado de los caminos, así como en el conocimiento que ofrecen de los cultivos: huertas y alamedas, prados, olivares, viñedos y tierras de labor.

En el siglo XIX se produce un nuevo resurgir de Itálica, que coincide con la recuperación de su nombre clásico y con las vistas de Andalucía realizadas, sobre todo, por los pintores románticos británicos. El avance de las excavaciones en el 
s. XX, y en especial la recuperación de algunas calles de la ciudad y el descubrimiento de parte del graderío del teatro, suponen el nacimiento de una nueva visión sobre Itálica. Aunque el anfiteatro conserve su protagonismo, las imágenes de la primera mitad del s. XX comienzan a abrir la mirada hacia una Itálica más amplia y compleja, pero sobre todo desde la propia Itálica. Las vistas se dirigen hacia la cornisa del Aljarafe, la vega y el Guadalquivir. También son de gran interés las vistas sobre el pueblo de Santiponce y hacia Sevilla (ZOIDO, 2013).

\subsubsection{Análisis de las condiciones del itinerario}

El análisis de las condiciones de la vía se ha realizado a partir del trabajo de campo y del estudio de la documentación histórica y cartográfica, que permite constatar las distintas situaciones en las que se encuentra el itinerario por lo que respecta a sus características formales y perceptivas.

\section{a. Condiciones de la vía}

La primera aproximación al análisis requiere realizar un recorrido por la vía pecuaria objeto de estudio que permita reconocer por donde discurre el itinerario y sus condiciones generales más básicas, como el estado del firme y la vegetación existente.

El comienzo del itinerario, abordándolo desde la ciudad de Sevilla, se inicia en las inmediaciones de Torre Triana y continúa con un sentido este-oeste recorriendo parte del viario urbano hasta el paso subterráneo que salva la carretera de Cádiz-Huelva. Tras este paso continúa en dirección oeste hacia Camas a través del puente de la Señorita y enlaza con el recorrido del Corredor Verde que transcurre paralelo al río Guadalquivir por un camino compactado con albero, en dirección norte.

Esta primera parte del recorrido se encuentra en su mayor parte bajo un efecto de atrincheramiento propiciado por la vegetación ribereña y por el talud correspondiente a las obras de defensa hidrológica, circunstancia que condiciona notablemente las vistas laterales.

Continuando el recorrido se accede al trazado original del cordel de Gambogaz a partir de la desviación hacia el cortijo del mismo nombre (ver FIG.6), y sigue en dirección noroeste hasta el punto de confluencia con el viaducto de Itálica (SE-30).

Esta sección del recorrido se desarrolla por un terreno llano, con un trazado recto que permite una gran amplitud de vistas por la propia horizontalidad que presenta la vega

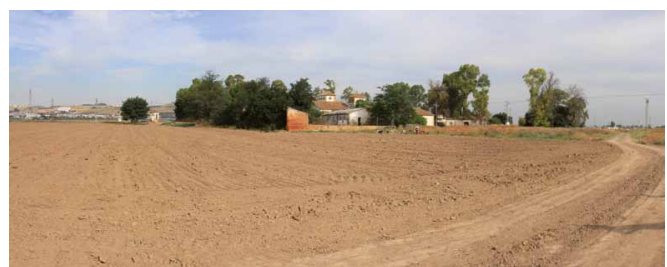

FIG. 6/ Paso del cordel de Gambogaz junto al cortijo que le da nombre.

Fuente: CEPT.

de Sevilla y por la ausencia de vegetación arbórea a excepción de la existente en las inmediaciones del cortijo de Gambogaz, donde destaca la presencia de una arboleda de cierto interés.

A partir de aquí toman protagonismo dentro de la vía pecuaria las grandes infraestructuras existentes en el territorio que atraviesan esta parte de la vega en condiciones sobreelevadas para evitar posibles inundaciones debido a los recurrentes desbordamientos de las aguas del río Guadalquivir: el viaducto de Itálica, la carretera E-803 (Autovía Ruta de la Plata) que se desarrolla en talud y el viaducto del ferrocarril de Sevilla a Huelva.

Se trata de una carretera asfaltada, con ausencia de bermas laterales y que se encuentra algo encajada, debido fundamentalmente a las citadas infraestructuras. La vegetación está asociada principalmente a las lindes de parcelas donde se desarrollan los usos deportivos e industriales existentes, a las pantallas vegetales propias de las vías existentes y a la vegetación riparia asociada al cauce semipermanente que se desarrolla bajo la Autovía Ruta de la Plata.

La parte final del recorrido presenta abundante vegetación arbórea formada por paraísos, ailantus, adelfas y otras especies de carácter ornamental (palmeras, cipreses) debido a la existencia de dos construcciones destinadas principalmente a usos hosteleros y de restauración.

A poco más de $0,5 \mathrm{~km}$. existe una rotonda de circulación de salida y entrada de la SE-30 que conecta con la carretera nacional $\mathrm{N}-630$ (antigua Vía de la Plata). A partir de este punto, el Corredor Verde discurre en paralelo a la carretera N-630, y presenta un trazado asfaltado, sin arcén o berma lateral hasta que cruza un pequeño túnel que salva dicha carretera de conexión con el norte peninsular y vía de peregrinación al formar parte del itinerario de la Vía de la Plata del Camino de Santiago. De este modo se finaliza el recorrido en el 
núcleo urbano de Santiponce, a la altura del teatro romano de Itálica que forma parte del Conjunto Monumental Ruinas de Itálica.

\section{b. Conectividad y articulación}

La puesta en valor de itinerarios y vías que conecten ámbitos urbanos densamente poblados con su entorno natural próximo, tal y como plantean las nuevas estrategias de recuperación de vías pecuarias, suponen que dichos itinerarios discurran por un territorio con una densa red de infraestructuras que lo atraviesan y articulan.

El caso del Corredor Verde Metropolitano de Sevilla se ajusta a esta realidad, en especial la fase Il que transcurre por un pasillo natural de comunicaciones norte-sur que ha sido utilizado como tal desde los primeros momentos de ocupación histórica del territorio. Asimismo, la necesidad de salvar el elemento natural de mayor entidad en el conjunto de la vega, el curso del río Guadalquivir, ha dado lugar al desarrollo de infraestructuras que permitieran las conexiones este-oeste. A ello hay que añadirle el hecho de ser un espacio estratégico en las inmediaciones de la ciudad de Sevilla, cuya centralidad en la aglomeración urbana es indiscutible.

En este pasillo natural se han sucedido de manera casi paralela las tres grandes infraestructuras de la histórica Vía de la Plata que han conectado la ciudad de Sevilla con el norte peninsular: la A-8078, la N-630 y A-66. En la actualidad, las dos últimas están directamente relacionadas con el cordel de Gambogaz: la carretera nacional N-630, visible desde el cordel y con la que se encuentra al final del recorrido del mismo en la entrada a la localidad de Santiponce; y la A-66, Autovía Ruta de la Plata, que también se hace presente durante gran parte del recorrido, debiendo salvarse por un viaducto a la altura del polígono industrial Los Girasoles (Camas).

En lo que respecta a las infraestructuras que discurren en dirección este-oeste salvando el río Guadalquivir y que se cruzan en el recorrido del cordel de Gambogaz, hay que señalar la SE-30, que se salva por el viaducto de Itálica una vez pasado el puente del Alamillo y el viaducto del ferrocarril Sevilla-Huelva. Por otra parte, hay que destacar como otro paso este-oeste para salvar el río la importancia del puente de la Señorita, que permite el tránsito peatonal y de bicicletas y es la vía de acceso al cordel de Gambogaz desde la ciudad de Sevilla.
Desde el punto de vista de la conectividad del cordel de Gambogaz con otros itinerarios públicos y recreativos hay que señalar la existencia de diversas infraestructuras pertenecientes a distintas administraciones públicas, como otros tramos del Corredor Verde, el trazado de la vía de peregrinación de la Vía de la Plata del Camino de Santiago, itinerarios ciclistas del Plan Andaluz de la Bicicleta, así como la Vía Verde de Ruinas de Itálica a Cala.

Esta conectividad del cordel de Gambogaz no se limita sólo a otros caminos e itinerarios, sino que posibilita el acceso y conexión con algunos espacios libres de interés de la aglomeración urbana de Sevilla, conformando una parte de la red de espacios libres metropolitanos e interconectados tal y como se determina en los documentos de planificación física del ámbito. Dentro de estos espacios públicos destacan especialmente las riberas del Guadalquivir, el Parque Metropolitano de Sevilla y el Parque Agrario de Camas.

\section{c. Condiciones escénicas y visibilidad}

Como ya se ha señalado, el territorio por el que transcurre el cordel de Gambogaz tiene unas condiciones topográficas determinantes en relación con la visibilidad del itinerario, existiendo una gran intervisibilidad entre la Ilanura aluvial del Guadalquivir en el fondo de valle y los espacios elevados próximos, como el escarpe del Aljarafe en la margen derecha del río.

Para abordar el tratamiento de las condiciones escénicas y de visibilidad de la vía pecuaria considerada se ha analizado el grado de exposición visual del entorno, así como las características específicas del propio recorrido desde el que se obtienen vistas de elementos o referentes visuales destacados.

En relación con la exposición visual, concepto que específicamente hace referencia al número de veces que un determinado espacio resulta visible desde un conjunto de puntos de observación, se han establecido tres categorías: muy alta, alta y moderada exposición visual.

- Muy alta exposición visual: el hecho geográfico fundamental en relación con esta categoría es el escarpe del Aljarafe en la margen derecha del río. La amplitud del valle y la elevación de esta cornisa permiten obtener vistas de estas elevaciones desde gran parte del recorrido del cordel. Por lo que respecta a la margen izquierda, los elementos arbóreos 


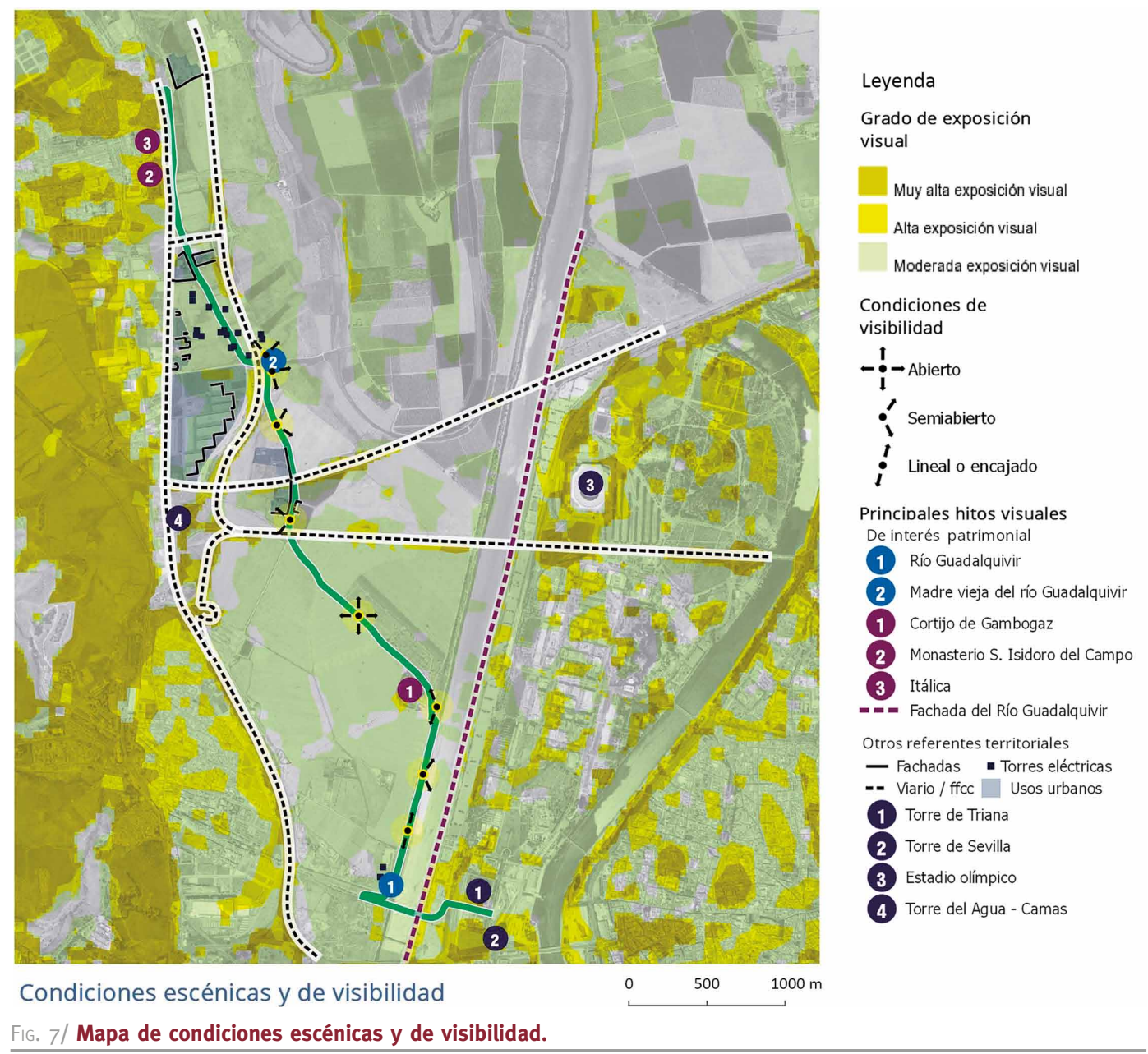

Fuente: Elaboración propia.

de la ribera del río se convierten en los más visibles desde el recorrido, así como las edificaciones más elevadas del sector norte de la Cartuja y, en un tercer plano, la fachada urbana interior de la dársena del Guadalquivir.

- Alta exposición visual: dentro de esta categoría se incluyen aquellas edificaciones de las localidades de Camas y Santiponce más próximas a las infraestructuras viarias, así como otras edificaciones destacadas de la ciudad de Sevilla.

- Moderada exposición visual: gran parte del valle del Guadalquivir por cuyas proximidades transcurre el cordel de Gambogaz se encuentra en esta categoría, ya que si bien son espacios muy llanos la amplitud que poseen permiten estar moderadamente expuestos a la visión desde el itinerario.

Por lo que respecta a visibilidad específica del cordel de Gambogaz (FIG. 7), hay que señalar que, al tratarse de un trazado lineal, son las condiciones de la topografía y de la vegetación del ámbito por el que discurre la vía las que tienen una mayor incidencia en la profundidad de las vistas frontales y laterales que se pueden obtener desde la misma.

Estas condiciones de visibilidad se determinan en función de la longitud y amplitud que alcanza la vista al recorrer el itinerario, pudiéndose distinguir desde vistas abiertas o semiabiertas a vistas completamente encajadas o cerradas.

Las vistas abiertas, que se caracterizan por tener una amplitud alta o panorámica y una profundidad también elevada, se concentran en el cordel de Gambogaz en el tramo que discurre entre el cortijo del mismo nombre y el viaducto de Itálica, al atravesar por tierras de labor con una cierta extensión, así como en el puente de la Señorita desde donde se obtienen amplias vistas del río Guadalquivir. 
Por otra parte, las vistas semiabiertas son las más comunes en el conjunto del recorrido, pudiendo alcanzar una longitud de visión de hasta $1,5 \mathrm{~km}$. pero con una amplitud media o parcial del campo visual. Ejemplos de estas vistas se localizan en las proximidades del cortijo de Gambogaz y en las proximidades de la fachada este del polígono industrial Los Girasoles, que ofrecen vistas hacia la vega del Guadalquivir y la cornisa del Aljarafe.

Finalmente, algunos de los tramos del recorrido presentan un campo visual lineal o cerrado donde la vista se encaja con una escasa amplitud lateral y con una profundidad media que no alcanza a la visión de un tercer plano. El tramo más representativo en este sentido se corresponde con la primera parte del recorrido cuando discurre por la margen derecha del Guadalquivir en dirección al cortijo de Gambogaz, si bien existen algunas ventanas propiciadas por la existencia de elementos arbóreos de escaso porte o por la ausencia de vegetación, que muestran vistas del curso de agua y de la otra margen del río.

En lo que respecta a los principales hitos hay que señalar que se consideran así los puntos o elementos de atracción visual que focalizan las vistas del territorio en el que se localizan y sirven como puntos de orientación o de referencia dentro del campo visual en el que se sitúan.

Cumpliendo estas funciones, es posible identificar elementos visualmente destacados y con interés patrimonial, como es el caso en el cordel de Gambogaz del río Guadalquivir y la Madre Vieja, del cortijo de Gambogaz, del monasterio de San Isidoro del Campo o del teatro romano de Itálica.

Asimismo, existen otros elementos destacados por ser referentes visuales de gran entidad en el ámbito que, al igual que en el caso anterior, son muy visibles desde distintos puntos del recorrido y se convierten en elementos de referencia y orientación cuando se recorre el cordel. Es el caso de la Torre Sevilla, la Torre Triana o el estadio olímpico de Sevilla en la margen izquierda del río o de la torre de EMASESA de Camas en la margen derecha.

\section{d. Identificación de recursos patrimoniales}

En el entorno del itinerario del cordel de Gambogaz existen referentes patrimoniales de gran entidad, tanto de carácter natural como cultural, que suponen un aliciente para el recorrido recreativo y didáctico por el mismo.

En lo que respecta a los referentes naturales destaca especialmente el río Guadalquivir, un elemento estructural de primer orden en la conformación de la ciudad de Sevilla y su entorno, que condicionó el origen de la ciudad y su evolución histórica. En la búsqueda de una solución por controlar las inundaciones recurrentes se realizaron en el curso bajo del Guadalquivir desde finales del siglo XVIII sucesivas cortas para modificar el trazado del río a su paso por la ciudad. La última de estas grandes intervenciones fue la corta de la Cartuja (1982), determinante en la reorganización del espacio que recorre el cordel de Gambogaz. Por una parte, supuso una ruptura del trazado histórico de esta vía pecuaria, al quedar cortado el tramo que unía el monasterio de la Cartuja con el cortijo de Gambogaz por el paso del nuevo cauce artificial del río; pero, por otra parte, la presencia de este brazo y de su vegetación de ribera asociada se constituye en un recurso natural de gran relevancia para el Corredor Verde Metropolitano de Sevilla.

Otro referente, aunque más difícil de identificar visualmente, es la Madre Vieja del Guadalquivir, un brazo secundario de este río que transcurría paralelo al mismo entre Santiponce y San Juan de Aznalfarache y que conectaba con el cauce principal a través de uno de los tramos del Rivera de Huelva. El cauce de la Madre Vieja fue sufriendo diversas modificaciones hasta su desaparición, pero algunos pequeños cursos semipermanentes de agua han ocupado algunos tramos, permitiendo la vegetación de ribera asociada a los mismos observar por donde podía transcurrir.

Finalmente, otro elemento natural a destacar es la cornisa norte del Aljarafe, cuya relevancia territorial en el conjunto del ámbito la convierte en un referente ambiental y paisajístico de primer orden.

En relación con el patrimonio cultural presente a lo largo del recorrido se cuenta con elementos muy destacados y diversos en cuanto a entidad, tipología y época histórica, hecho que supone una oportunidad de conocer los procesos históricos más relevantes en la conformación de este espacio. En este sentido y de manera sintética se identifican: el teatro romano de la ciudad de Itálica, construido entre los siglos I a. C. y I d. C., el enclave monumental de San Isidoro del Campo, monasterio medieval actualmente perteneciente a la Red de Espacios Culturales de Andalucía y el cortijo de Gambogaz, una de las mejor documentadas y más paradigmáticas explotaciones agrícolas de toda Andalucía con origen en una alquería medieval.

\section{e. Incidencias territoriales y urbanísticas}

El cordel de Gambogaz discurre por la Aglomeración Urbana de Sevilla que ocupa una superficie de $4.900 \mathrm{Km}^{2}$, compuesta por $46 \mathrm{mu}$ nicipios y con una población total de 1.535.379 habitantes (INE, 2016). 
En este contexto territorial, donde las dinámicas y los flujos que se suceden tienen una clara vocación metropolitana, resulta de interés revisar las consideraciones que los documentos de planificación física, territoriales y urbanísticos, establecen para el cordel de Gambogaz y su entorno más próximo.

Desde una escala regional y subregional los documentos de planificación física que tienen incidencia en el cordel de Gambogaz y su entorno próximo son el Plan de Ordenación del Territorio de Andalucía (POTA, 2006) y el Plan de Ordenación del Territorio de la Aglomeración Urbana de Sevilla (POTAUS, 2009). Estos documentos tienen en común, en relación con el cordel de Gambogaz, una directriz general de protección ambiental y patrimonial de los espacios sobresalientes -en los que se incluyen la red de vías pecuarias y las márgenes fluviales-, que potencie su recuperación y su inclusión en las redes de espacios libres y fomento del uso público.

En esta misma línea se manifiestan los documentos de planificación municipal, que en el caso del cordel afecta a los municipios de Sevilla (PGOU de Sevilla, 2006), Camas (PGOU de Camas, 2000) y Santiponce (NNSS de Santiponce, 1993). En todos ellos se contemplan las afecciones derivadas de las leyes sectoriales y establecen su condición de suelo no urbanizable, si bien son conscientes de que esta circunstancia no siempre ha sido respetada, abogando todos por la necesidad del deslinde y amojonamiento de la vía pecuaria y su incorporación en el sistema de espacios libres metropolitano.

\subsection{Diagnóstico paisajístico del itinerario}

El diagnóstico en relación con los recursos paisajísticos del cordel de Gambogaz se centra en la identificación de manera sintética de los principales valores y conflictos que se observan en el ámbito de estudio, especialmente aquellos relacionados con el itinerario de la vía pecuaria (FIG. 8).

\subsubsection{Potencialidades y recursos}

En relación con los recursos y potencialidades y de manera muy sintética, se recogen tanto los principales valores paisajísticos del propio ámbito como aquellas circunstancias y elementos que

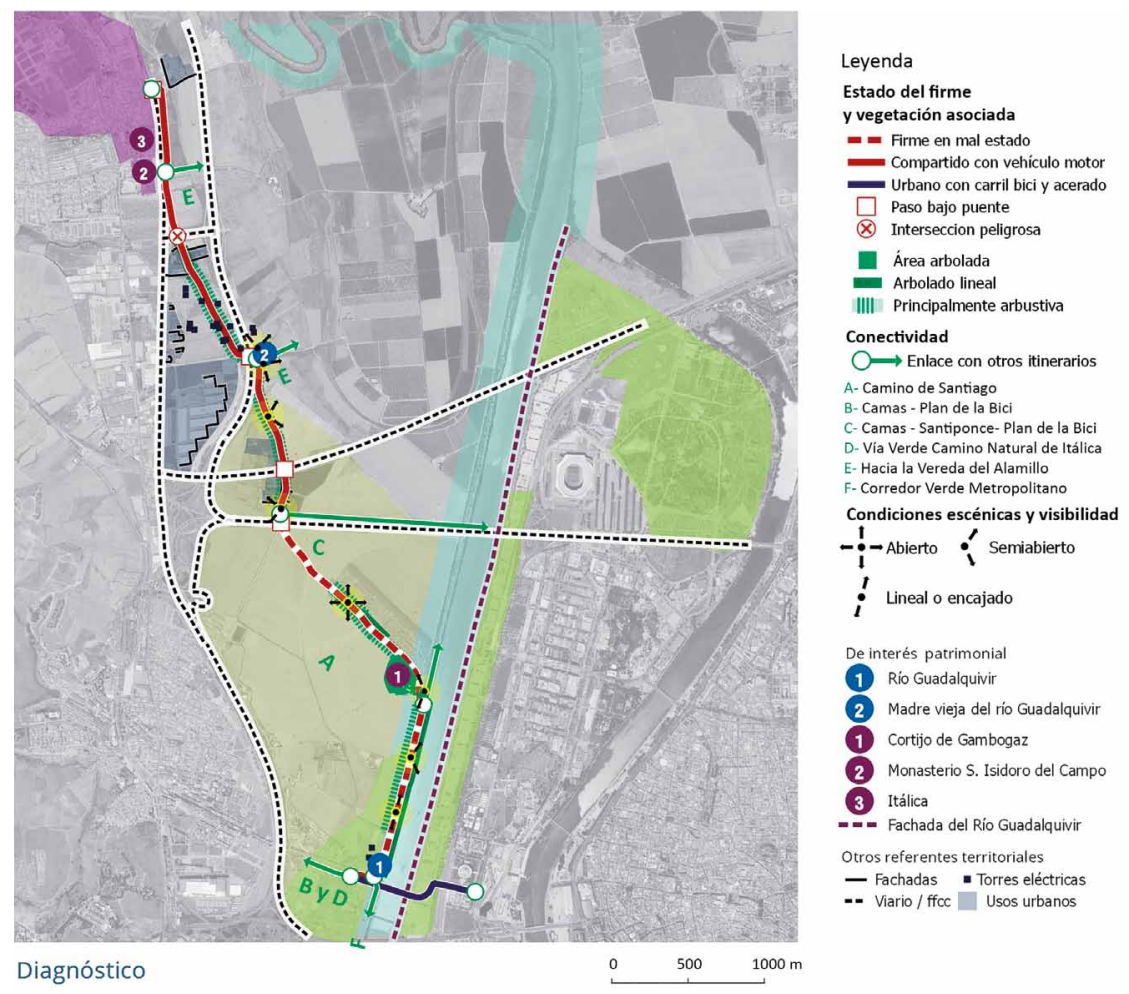

FIG. 8/ Mapa de diagnóstico. 
contribuyen de manera significativa a una mejor calidad paisajística del territorio por el que transcurre el cordel de Gambogaz. A continuación, se relacionan las principales potencialidades identificadas:

- El itinerario permite el acceso a un ámbito estratégico en el contexto de la aglomeración metropolitana de la ciudad de Sevilla, donde además se localizan espacios que cuentan con valores ambientales y paisajísticos como el río Guadalquivir y su vega y la cornisa del Aljarafe.

- Las condiciones escénicas del itinerario favorecen el establecimiento de vistas de conjunto sobre el sector noroccidental de la aglomeración urbana de Sevilla, así como una gran variedad de situaciones a medida que se recorre el camino: campos visuales abiertos o semiabiertos, ventanas hacia espacios sobresalientes, vistas de gran amplitud.

- El cordel de Gambogaz forma parte de la red de vías pecuarias existentes en la provincia, muchas de ellas recuperadas para el uso público, por lo que se articula una red de itinerarios relacionados con el uso recreativo y el disfrute social. Esta red está conectada con otros itinerarios verdes que permiten el recorrido, tanto peatonal como ciclista, de manera continua por el ámbito.

- Existen relevantes manifestaciones patrimoniales asociadas al itinerario que, debido a su emplazamiento y entidad, se convierten en importantes hitos paisajísticos del recorrido: cortijo de Gambogaz, monasterio de San Isidoro del Campo, Itálica (FIG. 9).

- La conectividad del cordel no sólo se establece con otros itinerarios de interés, sino que además conecta con espacios libres del ámbito metropolitano, contribuyendo a la consolidación de la red de espacios libres, metropolitanos y municipales, recogidos en la planificación física del territorio.

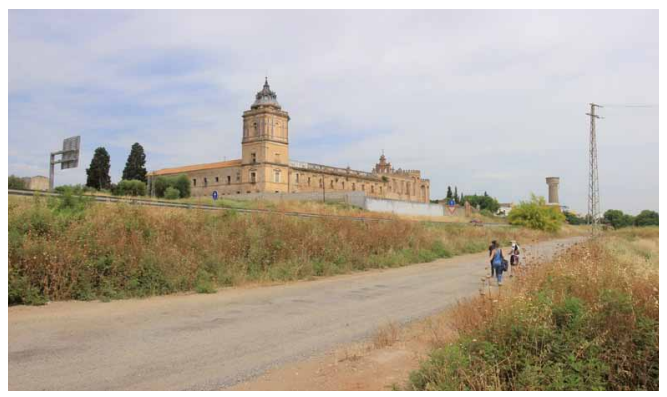

FIG. 9/ Cordel de Gambogaz a su paso por el monasterio de San Isidoro del Campo.
- La importancia del emplazamiento junto al eje vertebrador de la aglomeración urbana de Sevilla, como es el río Guadalquivir, así como la compleja herencia histórica de este territorio (Ruta de la Plata, trashumancia, restos arqueológicos) confieren a este espacio y al itinerario del cordel de Gambogaz una gran potencialidad para poner en valor esta riqueza territorial y paisajística existente.

\subsubsection{Conflictos y amenazas}

Por lo que respecta a las circunstancias que se pueden identificar como conflictivas o degradantes para la calidad paisajística del cordel analizado, se pueden señalar las siguientes:

- El uso recreativo y peatonal para el que se conciben las vías pecuarias en la actualidad no siempre se puede desarrollar dadas las condiciones en las que se encuentran algunos tramos del viario, con un firme inadecuado para el tránsito en bicicleta o de manera peatonal.

- La ausencia de vegetación de porte arbóreo en la mayor parte de los tramos del recorrido, así como las escasas zonas de sombra que permitan la estancia y el descanso.

- La compatibilidad de usos, tanto de carácter recreativo como de itinerario de acceso a instalaciones próximas, resulta difícil cuando estas últimas se realizan con vehículos motorizados de gran envergadura, existiendo tramos y puntos de cierta peligrosidad por la confluencia de tramos peatonales y rodados.

- Estos usos identificados requieren la existencia de una señalización clara en los accesos y cruces con otras vías que extreme las condiciones de seguridad en el tránsito y evite puntos de peligro. Aeste déficit de señalética reglada para el tráfico rodado se suma la escasez de elementos de identificación que orienten al usuario respecto al itinerario a seguir, así como otros de carácter divulgativo que aporten una información de interés sobre los elementos territoriales próximos.

- La alta incidencia visual de numerosas infraestructuras, tanto viarias y ferroviarias como relacionadas con la red eléctrica, que tienen una gran presencia a lo largo del recorrido. Igualmente, existen diversas traseras de polígonos industriales cercanos, así como edificaciones y construcciones de actividades terciarias con escasa integración paisajística. Asimismo, es posible encontrar en las proximidades del cordel algunas edificaciones que se encuentran en estado ruinoso y muy degradadas, circunstancia que no contribuye a la calidad de la experiencia paisajística a lo largo del recorrido. 


\subsection{Criterios para la cualificación paisajística del itinerario}

Como criterios para la cualificación paisajística del itinerario se contemplan un conjunto de ideas que pueden ser consideradas para la articulación de actuaciones concretas, vinculadas, tanto a la mejora de las condiciones de estancia de la propia vía pecuaria, como al fomento del acceso y la comprensión de los paisajes que esta recorre. En cualquier caso, estas ideas se plantean en un nivel propositivo intermedio, no sustituyendo en ninguna circunstancia al necesario proyecto específico de formalización y cualificación.

Estas ideas se agrupan en tres grandes categorías y a su vez se subdividen en objetivos dentro de cada una de ellas ${ }^{3}$ :

\subsubsection{Tratamiento de la vía y su señalización}

El buen estado de la vía y una adecuada señalización suponen elementos básicos para garantizar la realización del recorrido en unas condiciones apropiadas de comodidad y seguridad, permitiendo que el viandante o ciclista pueda disfrutar de la experiencia sensorial de forma plena. Dos aspectos son esenciales a tener en cuenta: por una parte, que el firme sea estable y libre de obstáculos, garantizando una efectiva separación con flujos de vehículos motorizados que comparten parte de los tramos. Por otra, que la señalización sea clara y sirva de orientación en todo el itinerario, indicando los accesos a la vía, enlaces con otros recorridos, puntos críticos con respecto a la seguridad (cruces, puentes, etc.) así como elementos de interés cultural o ambiental. Por tanto, los objetivos en la actuación deberían ser:

- Mejorar las condiciones de la vía: firme, puntos críticos y tramos compartidos con vehículos de motor.

- Estrategia de señalética. Accesos, tramos, enlace con otras vías, espacios de interés y puntos peligrosos.

\subsubsection{Cualificación ambiental del recorrido}

La vegetación presente en la vía y la existencia de un pequeño equipamiento que la acompañe, son dos de los elementos que más contribuyen

\footnotetext{
${ }^{3}$ En el trabajo que ha dado lugar a este artículo se incluyen una serie de fichas con los posibles lugares de actuación, los criterios específicos y un conjunto de proyectos de
}

a generar unas condiciones de confort en el itinerario y a que se desarrollen diferentes actividades complementarias asociadas al propio recorrido. La cualificación de los márgenes con especies autóctonas que han ido desapareciendo, principalmente por la acción antrópica, puede contribuir a la integración ambiental de la vía pecuaria con una mejor adaptación climática y con poco mantenimiento (FIG.10). Estos criterios se articulan a partir de los siguientes objetivos:

- Generar áreas de sombra a lo largo del recorrido y de minimización de ciertos frentes tensionados por las urbanizaciones.

- Proveer zonas de estancia y de pequeño equipamiento asociado (bancos, fuentes, papeleras) en lugares estratégicos.

\subsubsection{Sensibilización, uso y disfrute paisajístico}

La vía pecuaria puede ser un excelente elemento que contribuya a la identificación de la ciudadanía con sus paisajes. Por una parte, es necesaria la adecuación con miradores de aquellos espacios con singulares condiciones de visibilidad, incorporando además información que permita mejorar la lectura territorial y el conocimiento y comprensión de los elementos relevantes existentes. Por otra parte, se debe favorecer la mejora de las cualidades escénicas de determinados espacios en los que las infraestructuras y los usos periurbanos dominan la escena, fomentando la realización de acciones creativas y singulares que puede conducir a su mayor integración o a crear nuevos paisajes, y enriquecer la relación que el usuario tiene con ellos. En este sentido, los objetivos prioritarios serían:

- Adecuar puntos con especiales cualidades visuales e integrar dispositivos de divulgación de los recursos patrimoniales y de los paisajes asociados.

- Integrar infraestructuras y otros impactos negativos: acciones artísticas y de tratamiento vegetal.

\section{Conclusiones}

Las vías pecuarias son un elemento territorial, ambiental, patrimonial y cultural de primer orden en el conjunto de España, cuyo origen se encuentra en la importancia de la actividad ganadera

referencia que pretenden ejemplificar diferentes intervenciones en contextos similares. 


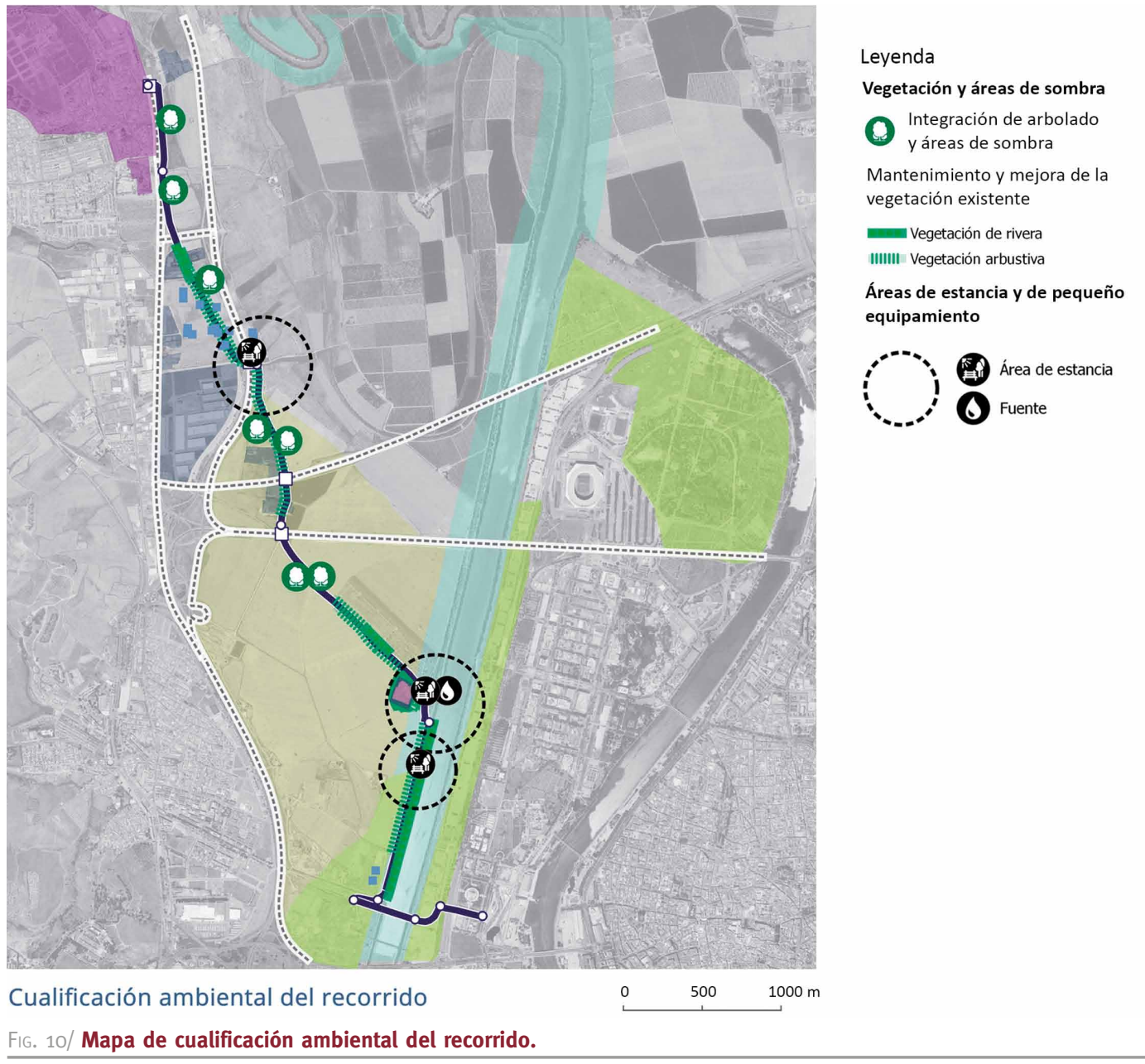

Fuente: Elaboración propia

y de la trashumancia a lo largo de la historia, siendo dichas vías consideradas como bienes de dominio público y formando parte, por lo tanto, del patrimonio de la sociedad.

Si bien hoy día el tránsito pecuario es la actividad tradicional y prioritaria de las vías pecuarias, la disminución de la trashumancia en la vida contemporánea ha abierto la posibilidad al desarrollo de otras actividades, complementarias y compatibles, en las mismas, tal y como recogen distintas regulaciones normativas vigentes: usos ecológicos y usos turístico-recreativos.

En el caso de Andalucía, existe una importante red de vías pecuarias deslindadas y en uso público que constituyen un patrimonio territorial y cultural de gran relevancia para la región, al tiempo que se configura como un valioso equipamiento para el acceso y disfrute de la naturaleza y del medio rural. Esta perspectiva de uso público acentúa su potencial como elemento para el acceso, conocimiento y disfrute del paisaje, en la medida en que su recorrido ofrece numerosas posibilidades y recursos: vistas del territorio circundante; claves explicativas de los usos y funciones -pasadas y presentes-, del itinerario; referencias de la construcción histórica del territorio por el que discurre, entre otros.

En este sentido, recorrer las vías pecuarias constituye un instrumento fundamental para descubrir el paisaje, asignándole valores y significados, y su recorrido no motorizado proporciona una forma de aproximación al territorio y a la naturaleza integradora y holística; aproximación en la que se conjugan los aspectos objetivos y subjetivos, materiales e inmateriales, visibles y no visibles, presentes y ausentes que se relacionan en torno a la noción de paisaje. 
Resulta imprescindible por tanto profundizar en el estudio de la vinculación existente entre paisaje y vías pecuarias, que aún no ha sido suficientemente desarrollada y que podría sustentarse en la relación fundamental que existe entre paisaje y movimiento, donde la apreciación dinámica del territorio convierte un itinerario en un hilo conductor de una sucesión de paisajes.

Esta vinculación entre paisaje y vías pecuarias favorece el potencial de las mismas como dotaciones para la sensibilización y el disfrute paisajístico de la población, y contribuye a incrementar el aprecio social por los valores ambientales, culturales y escénicos de los distintos ámbitos geográficos por los que discurren dichas vías.

Además, resulta necesario el desarrollo de procesos metodológicos de análisis y reconocimiento de los valores paisajísticos asociados a las vías pecuarias, que permitan sistematizar su consideración y los posibles criterios de intervención. En este sentido es imprescindible abordar el tratamiento paisajístico de las vías pecuarias a distintas escalas, teniendo en cuenta tanto el paisaje interior de la vía como el contexto paisajístico de la misma.

Igualmente, desde el punto de vista metodológico es aconsejable desarrollar la noción de diversificación paisajística en relación con las vías pecuarias siguiendo distintos enfoques (diversificación ambiental, escénica, funcional, de significados) tomando en consideración los nuevos usos que tanto desde la administración como desde la ciudadanía se han ido incorporando.

Finalmente, la puesta en valor de las vías pecuarias y su paisaje, en tanto que recursos endógenos con los que cuentan los diversos territorios, puede contribuir a implementar modelos de desarrollo socioeconómicos sostenibles; así mismo, en la medida que favorecen el contacto con la naturaleza y el desarrollo de actividades saludables, las vías pecuarias contribuyen a la mejora de la calidad de vida de la población.

\section{Bibliografía}

Agencia de Obra Pública de la Junta de Andalucia (AOPJA) (2017): Las carreteras paisajísticas de Andalucía. Recurso para el disfrute y aprecio social del paisaje, Consejería de Fomento y Vivienda, Junta de Andalucía. Centro de Estudios Paisaje y Territorio (CEPT), Universidad de Sevilla.

ApPleYARD, D. \& LYNCH, L. \& MyeR, J.R. (1971): The view from the Road. Cambridge, The Massachusetts Institute of Technology, $58 \mathrm{pp}$.

Bertrand, M. J. (1978): Pratique de la ville. Paris, Masson, $210 \mathrm{pp}$.
Besse, J.M. (2010): El espacio del paisaje. En III Jornadas del Doctorado en Geografía. Desafíos Teóricos y Compromiso Social en la Argentina de Hoy. La Plata: Universidad Nacional de La Plata, <jornadasdocgeo.fahce.unlp.edu.ar/programa-2010> (14 febrero 2013).

CAPEL, H. (1973): Percepción del medio y comportamiento geográfico. Revista de Geografía, $\mathrm{n}^{\circ} 7$, pp. 58-150.

Caballero Sánchez, V. \& Domínguez Vela, J.J. \& Zoido NARANJo, F. (2016): Experiencia del paisaje, movilidad y red viaria. Sevilla, Consejería de Fomento y Vivienda, Agencia de Obra Pública de la Junta de Andalucía, Universidad de Sevilla, Centro de Estudios Paisaje y Territorio.

Calvo Salazar, M. (2001): Mesa debate Las Vías pecuarias y los Corredores Verdes en la Ordenación del Territorio. En Conferencia Internacional de Vías Pecuarias y Corredores Verdes. Chiclana de la Frontera 21-24 noviembre 2001. Junta de Andalucía.

Clavero Salvador, J. (2001): Función social de las Vías Pecuarias. En Conferencia Internacional de Vías Pecuarias y Corredores Verdes. Chiclana de la Frontera 21-24 noviembre 2001. Junta de Andalucía.

Consejo de Europa (2000): Convenio Europeo del Paisaje. Florencia. Editado en español en Convenio Europeo del Paisaje. Textos y comentarios. Madrid, Ministerio de Medio Ambiente.

Consejo de Gobierno de la Junta de Andalucía (2001): Plan para la Recuperación y Ordenación de la Red de Vías Pecuarias de la Comunidad Autónoma de Andalucía, aprobado mediante Acuerdo del Consejo de Gobierno de fecha 27 de marzo de 2000. BOJA 74/2001, de 30 de junio.

Corredor Verde del Área Metropolitana de SeVilla (2003): Sevilla, Dirección General de Educación Ambiental, Consejería de Medio Ambiente, Junta de Andalucía.

Cosgrove, D. (2002): Observando la naturaleza: el paisaje y el sentido europeo de la vista. Boletín de la Asociación de Geógrafos Españoles, n³4, pp. 63-89.

Decreto 155/1998, de 21 de julio, por el que se aprueba el Reglamento de Vías Pecuarias de la Comunidad Autónoma de Andalucía. Boletín Oficial de la Junta de Andalucía, no 87 de 4/8/1998.

ESPAÑOL ECHÁNIZ, I. (2007): Carretera, movilidad y percepción. Criterios para la gestión de la función paisajística de las carreteras. En: 1er Congreso Paisaje e Infraestructuras. Libro de Actas (pp. 455-473), Sevilla: Consejería de Obras Públicas y ViviendaCentro de Estudios Paisaje y Territorio.

Fernández Salinas, V. \& Silva Pérez, R. (2015): Los paisajes en movimiento. El conocimiento paisajístico de Andalucía a través de la carretera. En DE La Riva, J., IBARRA, P., Montorio \& R., Rodrigues, M. (Eds.) Análisis espacial y representación geográfica: innovación y aplicación (pp. 953-960), Zaragoza, Universidad de Zaragoza-AGE.

GovindA, A. (2014): La senda de las nubes blancas. Gerona, Atalanta, 393 pp.

IMA Informe de Medio Ambiente en Andalucía. Informe 2018(2018). REDIAM, Consejería de Medio Ambiente, Junta de Andalucía.

KeSsLeR, M. (2000): El paisaje y su sombra. Barcelona, Idea Books, 86 pp. 


\section{Estudios}

Ley 3/1995, de 23 de marzo, de vías pecuarias. $B O E$ № 71 de 24 de Marzo de 1995.

LUGINBÜHL, Y. (2007): Paisaje y calidad de vida. En 1er Congreso Paisaje e Infraestructuras. Libro de Actas (pp. 53-65), Sevilla, Consejería de Obras Públicas y Vivienda-Centro de Estudios Paisaje y Territorio.

Manteca Valdelande, V. (1995): Las vías pecuarias: evolución y normativa actual. Agricultura y Sociedad, no 76 (julio-septiembre), pp. 153-186.

Merleau-Ponty, M. (1975): Fenomenología de la percepción. Barcelona, Península, 469 pp.

Nogué I Font, J. (2007): El paisaje como constructo social. En J. Nogué (Ed.) La construcción social del paisaje (pp. 11-24), Madrid, Biblioteca Nueva.

NNSS: Normas Subsidiarias Municipales de Santiponce (1993): Ayuntamiento de Santiponce. Junta de Andalucía.

Ortega Chinchilla, M.J. (2010): Percepción y representación. El territorio andaluz en la cartografía manuscrita del siglo XVIII. Granada, Universidad de Granada, 346 pp.

POTA: Plan de Ordenación del Territorio de Andalucía (2006): Junta de Andalucía.

POTAUS: Plan de Ordenación del Territorio de la Aglomeración Urbana de Sevilla (2009): Junta de Andalucía.

PGOU: Plan General de Ordenación Urbana de Camas (2000): Ayuntamiento de Camas. Junta de Andalucía.

PGOU: Plan General de Ordenación Urbana de Sevilla (2006): Ayuntamiento de Sevilla. Junta de Andalucía.
Prada Llorente, E.I. (2005): Paisaje agrario: antropología de un territorio. Ciudad Y Territorio Estudios Territoriales (CyTET), 37(144), 343-372.

Roger, A. (2007): Breve tratado del paisaje. Madrid, Biblioteca Nueva, $211 \mathrm{pp}$.

Tuan, Y.F. (2007): Topofilia: un estudio de las percepciones, actitudes y valores sobre el entorno. Barcelona, Melusina, $351 \mathrm{pp}$.

- (2018): Espacio y lugar. Una perspectiva humanística. En J. NoguÉ (Ed.) Yi-Fu Tuan. El arte de la geografía (pp. 53-110), Barcelona, Icaria.

Zoido NARANuo, F. (Dir.) (2009): Carreteras Paisajísticas. Estudio para su Catalogación en Andalucía. Sevilla, Consejería de Obras Públicas y Transportes, Junta de Andalucía y Centro de Estudios Paisaje y Territorio.

— \& al. (2013): El paisaje en el Conjunto Arqueológico de Itálica. Sevilla, Consejería de Educación, Cultura y Deporte, Junta de Andalucía.

- (2014): Bases para la realización del Sistema Compartido de Información sobre el Paisaje de Andalucía (SCIPA). Aplicación a Sierra Morena. Sevilla, Consejería de Medio Ambiente y Ordenación del Territorio, Centro de Estudios Paisaje y Territorio.

— \& Rodriguez, J. (Dir.) (2015): Catálogo de Paisajes de la provincia de Sevilla. Sevilla, Centro de Estudios Paisaje y Territorio, Consejería de Medio Ambiente y Ordenación del Territorio.

Recibido: 18.12..2019; Revisado: 09.07.2020

Correo electrónico: c.venegas@paisajeyterritorio.es; N ORCID: https://orcid.org/0000-0001-8682-1130;

Correo: irena.garcia@paisajeyterritorio.es; No ORCID: : https://orcid.org/0000-0003-2018-1884;

Correo: j.rodriguez@paisajeyterritorio.es; NORCID: https://orcid.org/0000-0002-5202-6160;

Correo: acoronado@us.es; NºRCID: https://orcid.org/0000-0001-5702-9750;

Correo: velaboll@gmail.com; NºRCID: https://orcid.org/0000-0001-8366-4440;

Correo: bpedregal@us.es; No ORCID: https://orcid.org/0000-0003-1473-8463

Los autores agradecen los comentarios y sugerencias realizados por los evaluadores anónimos, que han contribuido a mejorar y enriquecer el manuscrito original. 